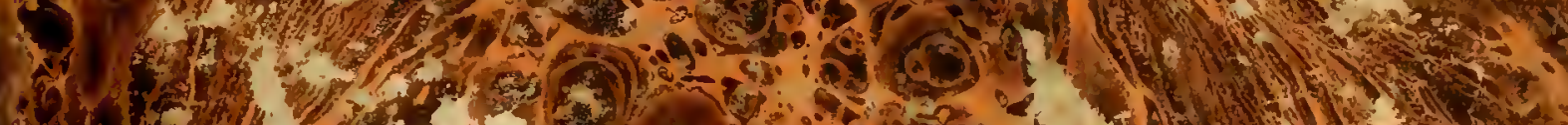

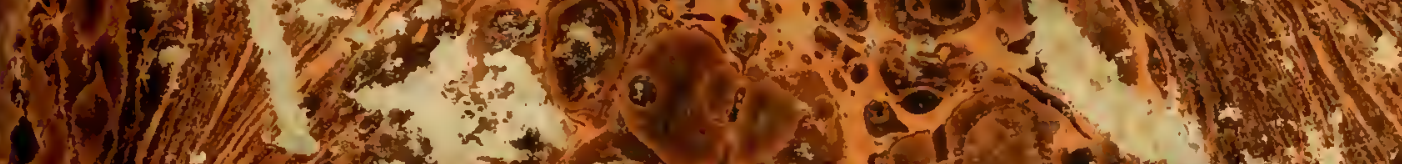

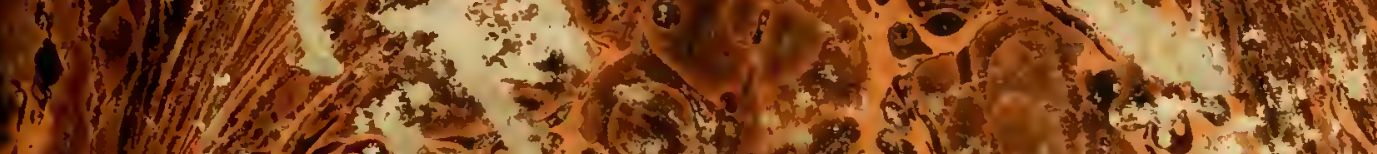

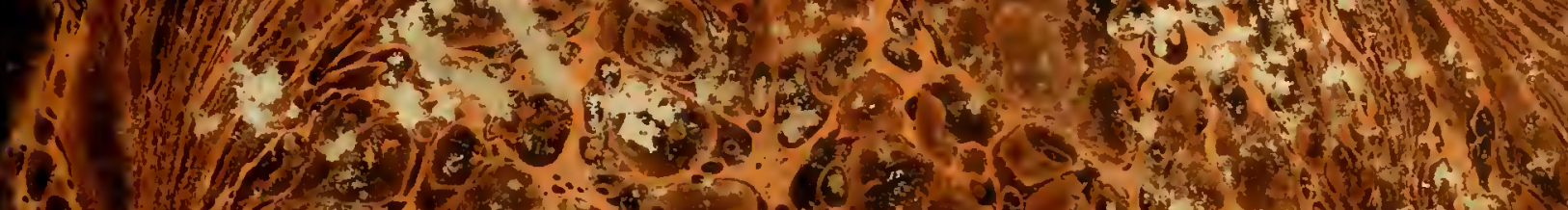

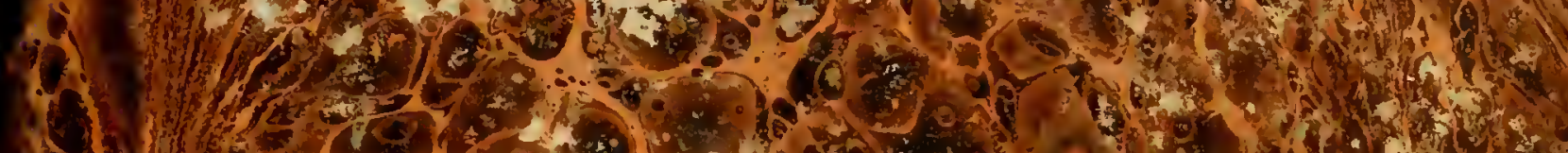

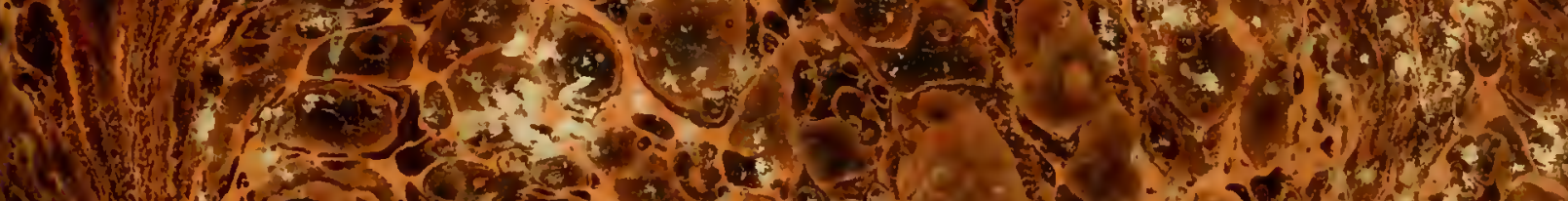

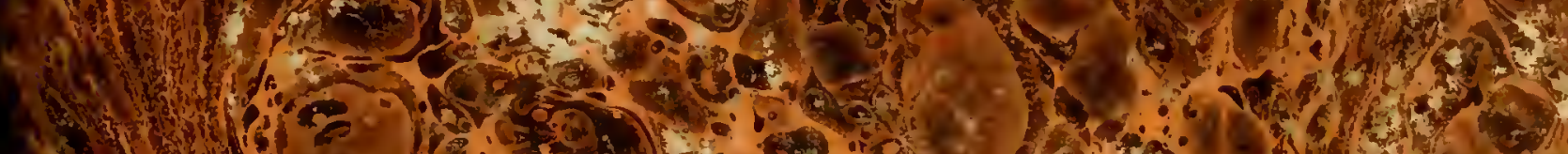

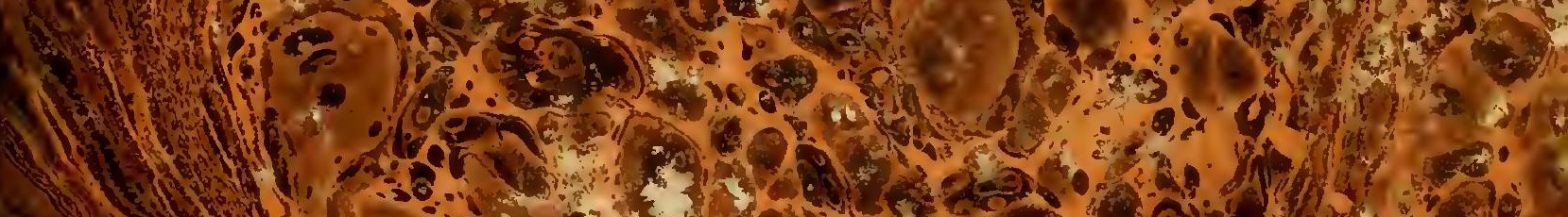

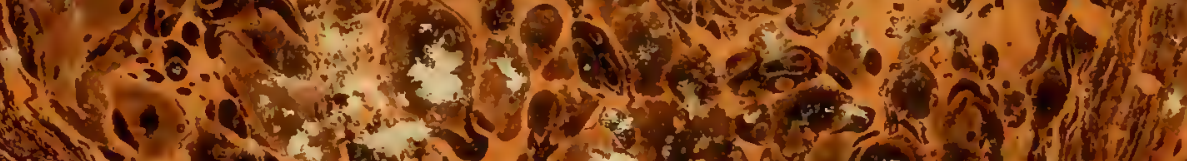

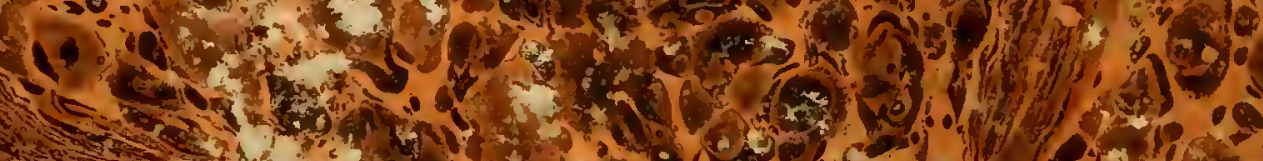

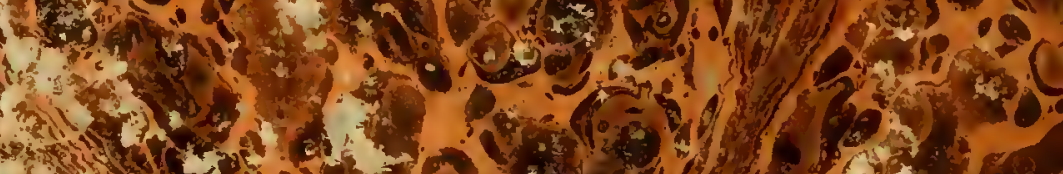

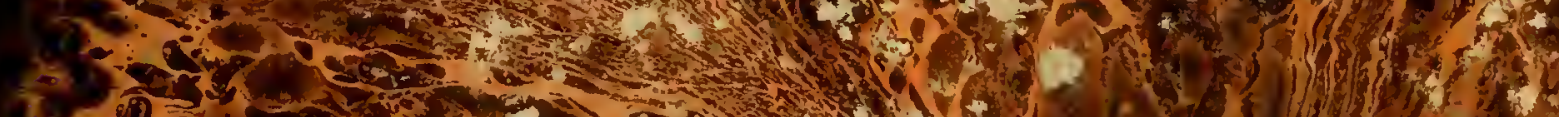

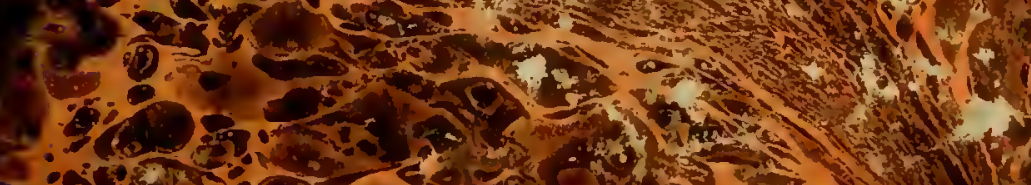
s.

1) 20110

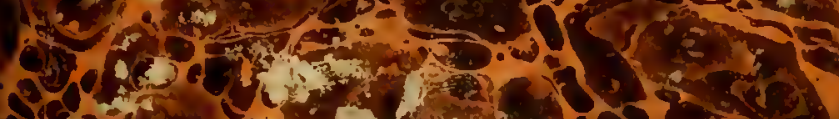

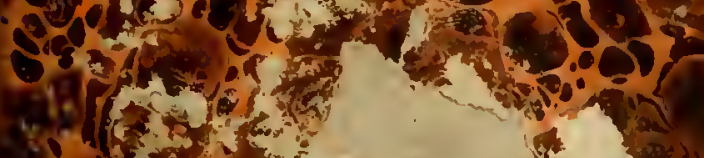
mets 1.1.1. -3. (3)

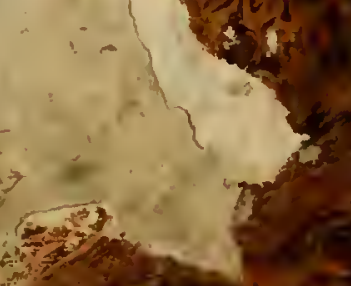


HARVARD UNIVERSITY

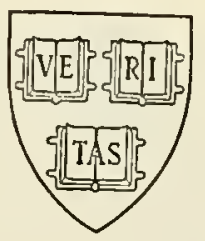

LIBRARY

OF THE

Museum of Comparative Zoölogy

Purchase

Boston Soclety of NaturaI History 

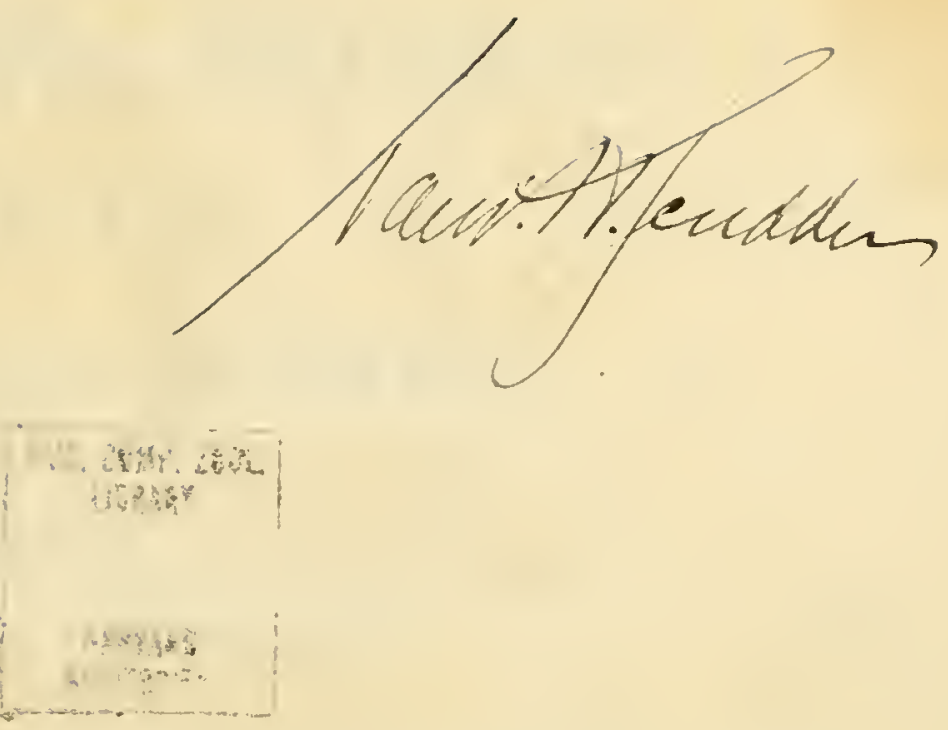



\title{
OSSERVAZIONI NATURALI
}

I N T O R N O

\author{
ALLE GAVALLETTE NOCIVE \\ D E L L A
}

CAMPANA ROMANA

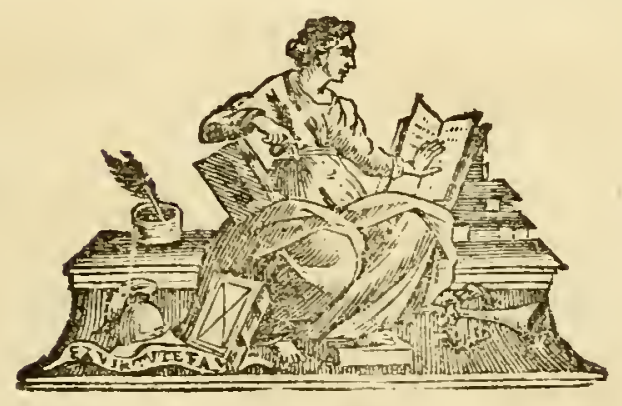

ROM A 1825 .

Presso Vincenzo Poggioli Stampatore della Rev. Cam. Apust.

Con Approvazione. 


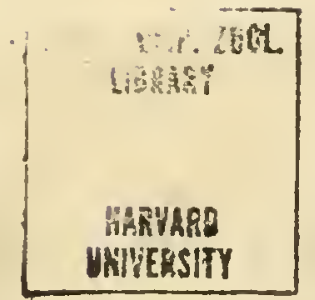


ALL'EMINENTISSIMO PRINCIPE'

IL SIG NOR GARDINALE

\title{
PIER FRANGESGO GALLEFFI
}

VESCO VO DI A L B A NO,

C A MERLENGO DELLA S.R. G.

LUIGI METAXA' E SEBASTIAXO ROLLR

\begin{abstract}
$\bar{H}_{R A}$ di non lieve importanza it determinare, se le locuste che da poch'anni indietro abbondarono fuor dell'usato nelle romane campagne, appartenessero alla Specie cl'Africa, cui si dà il nome di migratoria, o nascesser fra noi, e fossero al par di quella dannose. E mentre si avea da tutti per fermo provenir elleno d'oltremare, fu acutezza d' ingegno e zelo al sommo commendevole del Vostro sapientissimo Antecessore il muover dubbio sil di un preteso autentico fatto suvalorato da popolar tradizione.
\end{abstract}


Le osservazioni naturali, che in soddisfazione del proposto quesito presentiamo ora a Vostra Eminenza rivestita rlclle stesse attribuzioni $e$ delle stesse virtic, avendo per iscopo la pubblica utilitì, abbiam certa lusinga che sian per essere bene accolte. Se la locissta devastatrice è in realtí nativa d'Italia, se può prevenirsene la moltiplicazione; la speme degli agricoltori sarì in avvenir meno incerta, e meno esorbitanti le imposte, pel cui insolito aggravio gl'ingordi speculatori trasser sovente partito dai comnni disastri.

Gelosa e precipuca cura fu già per $V_{\text {oi }}$ il sovvenire $i$ menclici : l' attrial promozione, anzichè inaridir le sorgenti, ove solean dissetarsi, mette in Fostro potere il piil valido mezzo di prevenir l'indigenza; la quale, se fu talvolta al mal oprar consigliera, fu ancor madre delle arti, dell'agricoltura e del commercio, che dieron poi il bando alla lor sordida istitutrice. Vostra mercè adunque la pover. tì svellasi dal fianco del delitto, e le si dia per compagna l' agricoltura: le troppo larghe sovvenzioni fomentano il vizio e umiliano la virtic: "idcue humanitas vocabatur, cum pars servitutis esset. 5, La terra rende con usura quel che riceve : l'agricoltore parco ne' bisogni e ne' desiderj non è mai povero e non invidia l'altrui. Ecco il tributo che da noi si offre alla veritù: s'affatichin pure $i$ dedicanti a profondere elogi di ogni maniera ai lor Mecenati climerici: tutte esauriscano le formule dedicatorie per trasformare $i$ nani in Atlanti, gli etiopi in cigni; quanto a noi il linguaggio della prostituzione e della menzogna non può aver luogo, perchè rendiamo ciò ch' è dovuto; perchè gli encomj caratteristici di Vostra Eminenza non son da torsi ad imprestito; percliè dell' egida non abbisogna il nostro scritto, vantando per iscusa legittina l'obbedienza e il dovere. Voi, ed il I'ostro illustre Predecessore, che al nostro lavoro deste occasione, vita e alimento, lovete esserne $i$ giudici; tanto men severi, quanto piì illuminati. 


\section{INTRODUZIONE.}

E

$\mathrm{E}_{\mathrm{GLI}}$ è ben ragionevole il declamare contro taluni, che han fama di sapienti, $i$ quali riguardano una gran parte degli esseri come inutili o nocivi, e insorgon talvolta fino a lagnarsi della Provvideuza quasi autrice de'mali. La brama istintiva della verità e della scienza, di clıe abusar suole la comune degli nomini (brama scolpitaci nel cuore dall' Autor della natura per darcisi a conoscere nelle sue opere), spesso ne asconde il limite delle forze intellettuali, ne indebolisce il valore, ne devia la direzione: quindi è che ignorando presso che totalmente le leggi che governano il Globo e gli agenti e le cause motrici e i vincoli e l'armonia, ad onta di sua corta veduta costruisce arditi gindizj; e sulla base mal ferma di equivoci sperimenti, d'incerte osservazioni, di oscuri fatti e di sconnessi fenomeni sogna ipotesi e teorie; astrae, generalizza e deduce.

Mal si appongono adunque coloro, che nella ricerca delle verità naturali, invece di proporsi la conferma de'sentimenti di venerazione e di amore per la Divinità, concepiscon la vana lusinga di travederne i fini e di svelarne gli arcani (s'è pur lecito di parlare così umanamente di quell'Essere incomprensibile); ed è audacia e follia il dichiarar nocevole tuttociò, di cui a colpo d'occhio non sappiam ravvisare l'utilità. Serva d'esempio al nio dire la Classe anmirabile degl' insetti, clie quantunque appariscano i più dispregievoli tra $\mathrm{i}$ viventi e men degni delle nostre meditazioni; purr mon ostante qual riunione in essi di forze motrici, rual prodigioso istinto, qual complicata struttura, quale incomparabile perfezione!' Han dessi la piì gran parte nell' economia della natura, serbando inalterabile l'equilibrio fra il regno vegetabile e l' animale : consumano per loro alimento infiniti corpi organizzati, che sarian di gravissimo danno a tutto il resto delle Specie animali, non esclusa l'umana; ed è forse perciò eccessiva la loro fecondità, voracità e prontezza nel digerire. Non le sole api e la falena del gelso, 
( ${ }^{2}$ a cui i cinesi oltre la seta ritraggono splendide vernici $e$ fila atte alla pesca); non la sola cocciniglia del Messico (Coccus cacti) ci sono evidentemente utili, somministrando il micle, la cera, la seta e la porpora: altre larve non men preziose filan bozzoli spontaneanente sugli alberi salvatici del Chilì ; (1) nè sono men vivi i colori che si hanno dal Coccus Polonus, e dalle grana chermes (Coccus ilicis); nè obbliar si possono altre due Specie di Coccus, donde gl' indiani ricavano la gomma-lacca, e i cinesi le loro economiche faci; nè il Genere Crioceris, nè il Trombidinum tinctorium di Fabricius. E prodotto di una falena quella pece, che ogni an110 in gran copia si estrae dalla provincia della Chilchia (2); ed è forse una formica che trasforma certa resina vegetabile in succino, sostanza tuttor problematica. Che dirò di que' tumori vegetabili ( noci di galla), che il genere Cynips produce irritando e pungendo le corteccie, le foglie e ogni altra parte delle piante per deporvi le ova; delle quali morbose escrescenze altre servono alla Tintura, alla Chimica, alla Farmacia; altre (le galle che formansi sulla Glecoma hederacea, e sulla salvia dell ${ }^{\circ}$ isola di Creta) ad uso di $110 n$ ingrato commestibile?

E se volgonii alla Medicina, forza è che io rammenti il punteruolo del fiore del cardo (Curculio odontalgicus Fabr.) quale istantaneo calmante nelle odontalgie; il millepiedi (Oniscus Italicus Lin.) qual potente diuretico nell'idropisia; e il soffice e delicato nido della Formica fungosa di Fabr. qual valido astringente nelle emorragie delle arterie, e le tante specie de'Generi Mylabris e Meloe, nelle quali, non meno che nelle cantaridi, risicde il potere di vescicare la pelle.

Nè rechi sorpresa l'udire, che taluni insetti associansi all' agricoltore per secondarne le viste. Son pur dessi che ripurgano il suolo dalle erbe parassite e nocive; poiclı̀, o le estirpano dalla radice, o ne spossano il vigore, o le divorano adulte: son pur dessi che estendono i confini del regno vegetabile, caricandosi delle polveri fecondanti degli stami; e quelle trasportando sulle piante femmine, ne determinano la

(1) Molina Storia Nalur. del Chili p. 183.

(2) Molina ibiủ. p. 184. 
fecondazione (1). Non lieve utilità anzi ehe danno ne arrecano certe larve, denudando in parte quegli alberi che troppo lnssureggianti e frondosi sarian poreri di frutta; e delle frutta accelerano e promuovono la maturazione, e più aggradevoli $e$ pii saporite le rendono con pungerne a suo tempo la polpa, insinuandovi per entro le loro ova (Curculio, Attelabus, Tinea). Che piin? Chi non sa che i lor cadaveri ammonticchiati servon di pingne concime per infertilixe le piu ingrate e sterili terre (2)? E mentre le molecole organiche de $e^{2}$ loro corpi modificate dalla fermentazione arricchiscon da un lato l'agricoltura; cospiran dall'altro alla depurazione dell' atmosfera; poichè, o si tratta de' cadaverici avanzi di annose piante, e questi rodono ed aspergono de'loro umori, onde loro mercè tornan presto a profitto di quella stessa terra, cui rendono con usura l'alimento clie già ne trasser vivendo; o si tratta di escrementi, o di sostanze animali in putrefazione, che appestan 1'aria coi lor malefici effluvj; e quelli, o divoran rạpidamente, o sotterrano, o decompongono, o disperdono,o impastano con certo glutine che li rende piì atti a servir di letame; o fanno che se ne compisca in piu breve tempo la putrefazione, o vi depongon le ova, donde nascour poi piu migliaja di larve, che in poco d'ora distruggono i più giganteschi cadaveri. E qual delito non abbiam noi alle larve di tante Nevroptere abitatrici delle acque stagnanti, e in ispecie a quella della zanzara (Culex pipiens), la quale nutrendosi di quanto v' ha di organico in quelle veneficlie infusioni, ne rende meno insalubre il palustre miasma?

Nè fra i vantaggi che si han dagl'insetti è da trasandarsi il pingue alimento che somministrano ad infiniti Ordini e Generi di animali, detti perciò insettivori; la qual cosa

(1) Ve ne ha una Spccie (Cynips Ptenes) clue dcpone le ova nella semenza del fico salvatico precoce. I greci inflano molti di questi primi frutti, e li pongon vicini ai fichi tardivi : nell'occlio di questi s' introduce l'insetto carico di polvere fecondanle, e così ne accelcra la maturita e rende il frutto più delicato: qucsla operazione introdona in Fraucia da Tournefort chiamasi caprificazione. (Cuv. R.A.tom. 3. p. 4/1.)

(2) I cadaveri dell' Epliemera 'ulgata di Linnco formano la ricchezza di non poche popolazioni : Scopoli (entcmol. Carn. p. 264.) ci assicura, clie a Laz non v' ha contadino clue nel mese di Gingno di ciascun' anno ne raccolga meno di renti caxra. 
4

mentre assicura l' esistenza e la conservazione di tante Specie, previene altresi il disordine che avverrebbe dal turbato equilibrio per l'eccessiva moltiplicazione degl'insetti . Immensi stuoli di uccelli, vindici e cnstodi de' nostri campi divorano un gran numero de' pit nocevoli all'agricoltura; e il dar caccia, e il far preda di quelli senza limiti e senza riserve fu spesso cagione, che gl'insetti in certe regioni s'annientarono oltre omni credere, e non contenti di spogliar lo campagne, espulsero fin l'nomo dal snolo natio. Ma la strage che gli nccelli fan degl' insetti non sarebbe sufficiente e proporzional compenso alla loro fecondità : esistono famiglie d'insetti destinate a far guerra ai più nocivi e più fatali fra laro: sorgono dalla medesima Classe nemici implacabili che dan morte ad innumerabili eserciti : dobbiamo ai soli Icneumoni (famiglia estesissima d'insetti) niente meno che gli egizj al loro Icneumone quadiupede (Viverra Icneumon) che divora le ova de'Coccodrilli : gl' Icneumoni (dice Kirbi) facendo scempio della tipula del formento, serbano all'Inghilterra le messi, che ne sarebbero interamente distrutte : s'intrudono per ogni dove: non v'ha pe' bruchi asilo commuque recondito che sia loro sconoscinto ed inaccessibile : sorprendono le larve entro i cavi degli alberi, o sotto le corteccie, o fin anche nell'intcrno de"frutti : le pungono, e ne introducon le ova entro il corpo: sboccian da (pueste le larve degl'Icneitnoni, cui serve di pascolo il corpo stesso delle loro ospiti e involontarie nutrici. (I)

Finalmente che direm della nostra Specie medesima, che per suo vitto mette a tributo tutti gli esseri e tutto il Globo, e non risparmia gl'insetti? Gli antichi greci ( per tacere degli Acridofagi dei quali a suo tempo) avean per costume di provocar l' appetito mangiando la larva della cicala del Frassino, ch'essi chiamavano Tettigonia; (Cicada orni Lin.) (2) di quella stessa Specie, che pungendo gli ornelli, ne fa scaturire la manna. I romani solean friggere certe larve, che

(2) Fra gl' insetti parassiti, che distruggono annualmenle un' inumensa quantilà di altri insetti, devono annoverarsi i Generi Carabus, Cicindela, Mantis, Sphex, Yespa, Chrysis, Crabro, Formica, Libellula, Cimex, Asilus, Empis etc.

(2) Gentes vescuntur iis (cicadis) ad orientem; etiam Parthi opibus abundantes etc. ( Plin. hist. nat. lib. 11. cap. 36.) 
rintracciate ne' cavi delle quercie, avean cura $d$ 'impingnare mutrendole di farina ( $\mathrm{I}$ ): questi bruchi che denominavano cossus, non può credersi che fossero larve del cerviattolo (Lucanus cervus L.) perchè d'assai spiacevole odore. Anche a di nostri gl'indiani, i negri, gli ottentotti c gli americani servonsi ad uso di commestibile di varj bruchi appartenenti all'Ordine de' Coleopteri, che annidano nelle cavità degli alberi : tali sono il Cerambice (Cerambix Cervicornis L.) il tonchio delle palme, (Curculio palmarum Lin.) la cosi detta formica bianca (Termes fatale Lin.) ec. ec.

Per verità le Cavallette delle quali abbiamo a parlare non sono di tal natura benefica, che possa trarsene argomento a conferma e sostegno della mia tesi ; per altro se molte popolazioni ne son desolate ed afflitte dalla fame e dai morbi, alcune altre ne sono provvidamente nutrite; se la loro comparsa su di un territorio spoglia e denuda i più colti e fertili campi, la ricolta de'cereali, delle gramigne e delle fiutta complessivamente valutata è sempre piì diffusa, più universale e piit ricca, che la loro invasione e moltiplicazione. Non is da porsi in dubbio però, che, bilanciando l'immenso male col poco utile che se ne trae, quello a questo enormemente prevalga, quando le loro falangi diffondonsi per le intere provincie e regni ed imperj; e più formidabili d'ogni più elet-. trica nube s' addensano e si scaricano sulle campagne, e colla voracità del fuoco tutte inesorabilmente distruggono le. speranze del desolato agricoltore.

(1) Praggrandesque roborum delicatiore sunt in cibo: ( cossos ro= cant), atque etian forina saginati: lai quoque altiles sunt. (Plin. ihid. lib. 17. cap. 24.). 



\section{A R T I C O L O PR I M O}

\section{Caratteri zoologici della Famiglia cui spettano le Cavallette nocive.}

S.r. IL carattere essenziale dell'Ordine degli Ortopteri (1) ( cui corrisponde l'Ordine Ulonata di Fabricius, diramazione di quello degti Emipteri di Linneo) consiste nella disposizione degli astncei, o ali superiori (Hemelytrae), e delle inferiori (Alae) : quelle semi-membranose, flessibili, d'ordinario coriacee, la cui linea di contatto in istato di riposo non è naai retta: queste rette, piegate per thngo, o in dne sensi, per lo pin a modo di ventaglio : entrambe lineate da $\mathrm{co}-$ stole longitudinali e trasverse. A quest'Ordine appartiene il Genere Gryllus di Linneo, di che Latreille, e Lamark formarono la Famiglia Locustariae, che si distingue alle ali inclinate e distese sul corpo col margine interno più elevato dell' esterno : Civier, avendo rignardo alla robustezza e lmghezza delle estremità posteriori de' Generi che la compongono, le diè il nome di Saltatoria.

S. 2. I Locustarj, o Saltatori suddividonsi in molti Generi , fra i quali non mi occuperò che dei due, Locusta e Acrydium, peichè avendo entrambi de'caratteri in conune, e d'altronde al solo Genere Acrydium appartenendo le Specie eminentemente nocive, è di assoluta necessitì il distinguere in pratica l'un Genere dall'altro; pcr la qual confusione ne avvenne, che non fur mai determinato con sufficiente esattezza, se indigena, o straniera fosse la Specie desolatrice de' nostri campi. Il Genere Locusta di Fabriciuts (Sauterelle de' francesi, Tettigonia di Linneo) ha le antenne setolose, lunghissime, di molti e brevi articoli : il labbro superiore non fiastagliato : $l^{\prime}$ inferiore con quattro leggerissime incavature; le mandibole inarcate: le ali a tetto, inclinate : il volo agile, l'organo dello stridore negli astucci de' maschi : l' ultimo pajo di gambe lingo, forte, atto al salto : il tarso con quattro articoli: il passo lento e stentato: l'addomine delle femmine terminato da una specie di trapano, o

(1) De Geer in origine li denominò Dermopteri : questo nome fu inopportunamente cambiato da Olivier in quello di Ortopteri. 
8

punternolo di quattro lamine. Abita le prata non palustri, e le colline temperate. Sono comuni presso di noi le Specie viridissima, verrteivora, varia etc. tutte erbivore, ma poco. o nulla dannose.

\$. 3. Il Genere Acrydium di Geoffroy (C'riquet de' francesi, Locusta di Linneo) Ina le antenne filiformi, brevi, (rare volte compresse, ensiformi, subclavate ) di venti a venticinçue articoli : il capo ovoicle : tre occhictti (Stemmata) lisci, inegnali in distanza: ali grandi, larghe, per lo pii vivacemente colorite di torchino, o di rosso: il corsaletto d'ordinario carenato, e nelle Specie straniere ispido, verrncoso, bernoccoluto: le tibie spinose : i tarsi con tre articoli : la femmina senza punternolo. L'organo dello stridore (proprio de'masclij delle Specic non sociali) vario, ma più sovente nasce dall' attrito delle tibie posteriori cogli astucci. Larva ne' due Generi senz'ali : Ninfa con un principio d'ali. Il solo Genere Acrydium abbraccia le cavallette fatali, la cui fecondità e voracità è oltre ogni credere prodigiosa : le piu colte, ed amene campagne a vista d'occhio in isquallidi acesti riducono : i putridi effluvj de'loro cadaveri ammorbano le più salubri regioni. La Specie straniera piu formidabile è il Migratorizm : non mancan però altre Specie o native, o naturalizzate in- Europa (come quella che si è moltiplicata fra noi in (puesti ultini anni) il cui nocumento non è men funcsto, e men lieve : ecco $i$ caratteri di ambedue $i$ Generi posti a contatto, onte paragonarli e distinguerli agevoluente.

fren. Locesta Fabric.

Lim. S.N. by J. Gryllus tettigonia.

Latrcille H. N. 12.12g.Sanrerelle.

Iamark I1. N. 4.236.

Cuvier R.A.3.380.

Antennae Setaceae, praelongae , articulis numerosis minimis; labinm superius integrinm, inferins bifidum, laciniis intermediis minimis, interne sela subulata instructis : palpi qualuor obusi , inaeruales, filiformes: labiales, labii medio inserti: mandibula arcuata, apice tridentata : maxilla arcuata: tarsi quadrinrticulati : cou-
Gen. Acrydum. Geoffr.

Fabric. Gryllus.

Linn. 699. Gryllus locusía.

Latreille 12.1 \%9. Criquet.

Lamark t. 4. 240.

Curier R. A. t. 3.382.

Antennac filiformes, porrectac. brcres, crassae, articulis viginti ad viginti quinque distinctis : labium itiferius bifidutn, ovatum, elongatum, laciniis fornicatis: palpi labiales la. bii medio adnati: mandibula recta, crassa, obtusa, dentata: maxilla subarcuata, brevis: ocelli inacqualiter inter se dissiti : tarsi triarticulati: cauda foeminis non ensifera: alae 
da foeminis ensifera. Alae deflexae, rarius coloratae, inlerdum virescentes: stricloris organum in clylris situn, vitseum, speculiforme, maxibus proprium. exquisite plicatae, saepius coloratae rubescentes, vel caerulescentes, volatu diuturno, alto, valido: vorax, foecundum, interdum migraturium. Stridoris saepius organum ex femorum cum elytris attitu, in speciebus tantum non socialibus.

\section{A R T I C O L O I I.}

\section{Storia de' danni.}

S. 4. Fucane ogni credere la portentosa fecondità di cotesto malefico insetto, al cui voracissimo dente nulla resiste. La stridula fiamma clıe consuma le aride stoppie, la diffusione e la mortalità di un contagio (I), le furie d'Euro e di Noto, l'impeto d'incoercibil torrente, sono immagini orientali enfatiche, ma non molto esagerate degl' istantanei progressi delle Cavallette, della total distruzione de'vegetabili, del demndamento delie terre, dell'inutilità de'mezzi per impedirlo: uomini e bruti, o periscon d'inedia per la privazione de' cereali e delle gramigne, o di morbo epidemico ed epizootico, che insorge dalle putride esalazioni de' loro cadaveri risospinti a terra dalle crescenti maree. Gli animali stessi famelici per la sofierta pennria si adattano a rodere gli aridi steli sfuggiti alle ingorde falangi; e soffocato 1 'istinto alla scelta, in un con questi inghiottono i corpi delle estinte locuste, o dissetansi nelle acque stagnanti e tuttora in fermento per la sommersione di quelle.

S. 5. Per quanto ne dicon le storie, poche regioni non soggiacquero a simil calamità : İa patria delle più grandi e più nocive è l'oriente, poichè il calor di que'climi è oltre modo favorevole alla loro generazione. Fra i più orribili flagelli minacciati da Mosè (2), predetti da Gioele (3) v'era l'invasione delle locuste : ve', dice Gioele, come gli alberi sfron

(1) Pietro Bargeo le paragona alla scabbia; , .... cen curr longo procul orbe locustae Actae euris nostros se se effulcre per agros.

(2) Deuteronom. cap. 28. v. 38.39 .

(3) Joel. cap. 1. e 2. 
10

2, dati e denudati della loro corteccia biancheggiano : ve" co2, me gli armenti emaciati cercano indarno l'usato vercle ne' " pascoli: come ai sacrificj e alle libazioni mancan le uve, 2 e il formento ! I madianiti (1), e i solclati di Oloferne (2) nomansi forti, invincibili, innumerabili come gli eserciti delle locuste (3); il rouzio delle ali si paragona allo strepito de' carri, al calpestio de' cavalli, al tumulto de'combattenti : (4) or se ne esalta la forza, or se ne ammira l'industria e la regolarità de' lor voli (5) : Onero e Teocrito le rammentan piu volte : un poeta arabo merzionato da Bochart (6) con enlatici paragoni ne ingigantisce il potere: Maometto leggea nelle loro ali: , siamo l'esercito di Dio,, e sotto tal nome sono tuttor conoscinte e venerate dagli aralji. Saria lungo e dolente incarico il rammenorare le epoclie luttuose di miseria e di orrore, di che empierono le Cavallette le più ricclie ed estese popolazioni del Globo. Il soflio di un caldo vento che si lewò in sul mattino ne spinse in Egitto ( a punizione di quell'ostinato regnante, sotto la cui schiavitu geneva il popol di Dio) incalcolabili stuoli, che in brevissimo tempo divorarono erbe, alberi, frutta $\left(\frac{-}{6}\right)$ e quanto $\mathrm{V}^{2}$ era di verde ne'campi- Essendo consoli M. Plauzio Ipseo, e M. Fulvio Flacco (8) avvenne nella Numidia pe' cadaveri delle locuste insepolte una funestissinna cpidemia, la quale non risparmiò la gramigione romana che presidiara Utica, forte di trentamila soldati. Nè taccion le

(!) Jurlic. cap. 6. r. 15. cap. 7. r. 22.

(3) Ibid. 2. II.

(3) ...... tristesque locustas. In morem nebulae nitidum praetexere solem.

Marc. Polingen. Zodiac. lib. 8.

(4) Joel. ibid.

Jerem. cap. 46. v. 23.

Amos 4. 9.

Nahum. cap. 3. v. 15.17.

A pocal. cap. 9. v. 7.
(5) Caj. ad cdict. prov. lib. 29. til. 2. D. D. (Plin. lib. I1. cap. 29.) Tanto volant pennarum stridore, ut aliae alites credantur, solemque obmbrent, sollicite spectantibus populis, ne suas operiant terras.

(Salom. prov. 3o. 27.)

(i) Bochart Hierozon. p. 2. lib. 4. cap. 4.

(-) Exod. cap. 10. v. 12. et seq.

(8) Jul. Olsseq. deprodig. dell'A. di R. 629. v. Oros. hisı. 
storie, che or ne fu desolata la Mesopotamia e la Siria (nell'anno 677 ); or l'intera Tracia, or l'isola di Cipro ( 11 el r $56 j$ ); per lo che disperando talvolta i popoli di lor sussistenza, esposero (nel 1034) in rendita i proprj figlí, e abbandonaron la patria (1). L' esercito di Carlo XII accampato nella Bessarabia ( nel 1716) fu assalito da si gran copia di locuste, che volando fia i piedi de'cavalli, e sugrli occhi dei soldati, toglieano loro la vista della strada.

S. 6. E qui cade in acconcio osservare, che essendo le regioni meridionali più abbondanti delle maggiori e più noceroli Specie di carallette, fin dall'antichità più remota, forse per minorarne il numero, vi $\mathrm{s}^{2}$ introdusse il costume di mangiarle. Mrosè (2) le permise agli ebrei ad uso di commestibile; ma i Talmudisti più esatti non riconoscon per monda che una sola Specie, (l'acridium cristatum, o come altri rogliono una varietà del migratorium) sul cui torace, ( come sembra lor di vedere) leggesi scritta in carattcri ebraici la parola caser. Egli è verosimil perciò , che le locuste in realtà, e non già le radici, o le cime degli alberi, alimentassero nel deserto il divin Precursore (3). Fra gli Acridofagi ( mangiatori di cavallette) contansi una gran parte dei popoli delle Indie orientali ed occidentali, gli arabi, i parti, i tartari, i cinesi, i sirj, i persiani, gli ebrei, gli egizj, gli etiopi (4) : gli ottentotti nulla curando la distruzione dei lor vegetabili ne festeggian l'arrivo: son desse per certi popoli opportumo compenso alla sterilità e alla penuria de' viveri: sovente ne'mercati di Bagdad la vendita delle carni soffie avvilimento e ritardo pel numero delle locuste; e $v^{2}$ ha esempio di eserciti, che essendo sul punto di perir dalla fame, fur debitori di loro salvezza alla comparsa di queste (5). Le sole viventi servono di alimento: le femmine che non han deposte le ova stimansi più sngose e più pingui; ed è piì facile il dar loro la caccia, perchè

(1) Cedren. Hist. p. 6o4. ed. Basil. (Baron, ann. tom. 3. ), Plin. lib. 8. cap.29." Civitatem pulsam ab locustis in Africa.",

(2) Levit. cap. XI. $\nabla .21$. e 22.

(3) Malt. in Diosc. lib. 2. cap. 46. Vallisn. op. tom. r. p. 84.

4) V. Diodor. Sic. lib. 3. cap. 3. Strabon. Geograph. lib. 16. Matt. in Diosc. lib. 2. cap. 5 \%

(j) Porphir. de abstin. a carne lib. I. 
I 2

men pronte ed agili pel ventre preguo e per la brevità delle ali. $D^{\prime}$ ordinario $s^{\prime}$ acconciano per serbarle : tuffansi vive nell'acqua bollente, si rascirgano e si salano: talvolta per iscarsezza di derrate soglionsi disseccare e ridure in ispecie di polvere farinosa ad oggetto di farne pasta.

S. 6. Contasi che tal cibo formasse già la delizia dell' oratore Callimedonte: Celso lo reputa agevole alla rligestione (1) e incorruttibile nello stomaco : Cestoni lo vuol preferibile ai gambari : Ippocrate vanta le locuste ne' casi di soppressione di lochj (2), e Alessandro Tralliano le propone qual correttivo delle acrimonie e della bile (3). Non tutti però la pensano allo stesso modo. Aristofane è già sospetto d'ironia, quando le chiama più delicate de'tordi. T'alete mostrava apprezzarle ben poco, essendo uso dire, clue nou $v^{\prime}$ ha differenza fra il colono che riporta locuste in luogo di grano, e il tiranno che ama neglio comandare agli schiavi, che agli nomini. Non istarò a spaventarvi con Agatarchide (4) ( nè vò darvi per certo ciò che non credo) che minaccia agli acridofagi il divenire meno che nomini, e il dover condurre una breve e misera vita emaciati e deformi fra le inmagiuarie punture di alati pidocchi : mi atterrò ai più discreti, che incolpano le locuste come ree di addensamenti sanguigni, e nocive ai temperamenti melanconici. Galeno (5) avendo osservato, che gli storni le rendevano indecomposte per l'ano, giudicò con falsa analogia, che fossero indigeste anche per gli nomini : Mercuriale (5) ancor pin severo attribuisce alle locuste le schifose e mortali inpetigini di quei che abitano i lidi del mar rosso, e ne chiama in testimonio Diodoro di Sicilia $(\zeta)$. Noi il crediamo un vil cibo introdotto dalla necessità; non prezioso per certo; non però di assoluto nocumento, e nuolto meno venefico. Ma torniamo ai danni.

(1) Galeu. lib. 8. de composit. pharmacor.

(2) Hipp. Ginecl. lib. 1.

(3) Al. Trall. lib. ir. cap. de empiem.

(4) Aldorr. de ins. p. 44 r.

(5) De loc. affect. lib. 5.

(6) Lib. 2. var. lect. 20.

(z) Diod. Sic. ibidem. 
S. 7 . Che direm degli effetti che risentironsi ne'piu colit $\theta_{3}$ fertili stati d'Europa; nella Francia (negli anni 874 e 16 s5); nella Russia ( nel i 084 ), nella Polonia (nel 1535 e nel 154r), nella Germania (nel 1542 ), nelle Spagne (r)(dal i 75 fino al 1757 ) ? E dee farsi pur motto delle piì segnalate invasiuni, che afflisser l' Italia nostra, e principalmente la Lombardia, il Mantovano, il Bresciano ec. (2) (negli anni 232, 503 , $1271,1339,1477,1564)$ : ncll'anno 852 non v'era giorno in cui non ispogliassero 1 40 jugeri di terreno; e nell'anno di Roma 579 i romani presero il partito d'inviare in Puglia il pretore Sicinio (3) con un esercito per estirparle. In curanto a Rona , se Plinio chiamò le cavallette ira e peste degl' iddii (4); se Q. Calabro paragonò il loro gettarsi su i campi all'impeto con cui i trojani scagliaronsi contro i greci; se i romani avean samro al culto delle cavallette l'ottavo di delle calende di Decembre (5), convien dire, che ruesta nostra città fosse frequentemente soggetta ad esserne malnenata. Saran sempre di luttuosa memoria le devastazioni alrecate dalle cavallette alla campagna romana nel 1577 ; et essendo Pontefici Paolo $V$ (nel 1612 ), Alessandro VII (dal I6.53 fino al I655, anno antecedente a quello, in cui Roma fu afflitta dalla peste) (6), Stefano VI, Adriano II e III, ed Innocenzo XI (nel I 687 ); e le invasioni piǹ prossime ai nostri tempi furon descritte dal Dottor Francesco Scufonio (7) ( nel i 7 I 7 ) dall'anonimo fiorentimo (8) dal Zinanni (9) e più recentemente (nel 1807 ) dal Signor Luigi Dor

(:) Bowles introduzione alla stor. natur. e alla Geografia fisica di Spagna. Traduzione del Milizia Parma i -83. Torn. 2. pag. 1. a 25.

(2) Aldovr. ibid. p. 422 .

(3) Liv. decad. v. lib. 2.

(4) Plin. lib. 11.. cap. 29.

(j) Cael. Rhodig. lib. 4. 1. L. cap. 15.

(6) Gastald. de avert. et profl. peste p. $7 \mathrm{I}$.

(-) Osservazioui intorno alle cavallette, dislese da Francesco Scufonio Dout, di Filosofia e Medicina. (Nogli statuti dell'agricoltura di Roma, Ro$\operatorname{ma} 1718$. in $40^{\circ}$ )

(8) Relazione delle diligenze usate con felice successo nell' anno 1 -16. per distruggere le cavallctte nellc maremme di Pisa, Siena, Volterra ec. Firenze 1716 . in 8 .

(9) Zinanni osservazioni giornali sopra le cavallclte. Venezia 1,37. in $40^{\circ}$ (Nell' Opera delle ova e de'nidi degli uccelli) Le osservazioni del Zinanni sońo veridiclıe, esatte ed illustrate da piu tavole in rame: alla pag. 36. 


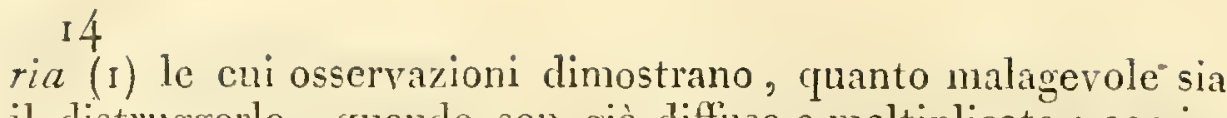
il distrnggerle, quando son già diffise e moltiplicate : coninciarono queste ad insorgere nel 1807 , e ad onta delle piu energiche, ma tarde, provvidenze, non se ne potè spegnere completanente l'infausto germe che nel i 8 r 5 , non senza clıe vi contribuisse il rigore e la dinturnità dell' inverno.

S. 8. Le cavallette poi che imprendiamo a descrivere, fin dalla metà di Magggio del 182 I dopo $u$ inverno asciutto e sereno si videro insorgere in istraordinaria quantita per varie parti della nostra campagna romana, e segnatamente lungo la strada di Fiumicino, pe'piani di Ponte-Galera, di Bracciano, di Tor di Quinto, e in diverse Tenute fuori di Porta Maggiore per la strada della Colonna. Si ebbe luogo a temere esser clleno di quella stessa voracissima Specie, che più volte trascurata e non estinta sul nascere, rapi una gran parte delle nostre messi, denudò $i$ verdi e ridenti prati, ed i ricchi pomarj in isquallidi deserti ridnsse; ed è ancor fresca la memoria delle dispendiose provvidenze, e non lievi sacrificj, che occorsero per estirparla. Per tal sospetto di pericolo che parve sovrastare alla romana agricoltura, il vigilantissimo Tribunale della Sagra Gonsulta fatto canto dalla sperienza del passato, ordinò fin d'allora ai suoi periti fisici (professori Morichini e Metaxà), che colla maggior possibile accuratezza e sollecitudine determinassero; I. Se tosse quella o nò la Gavalletta viaggiatrice di Tartaria (Acrydizum? ITigratorium Oliv.) creduta eminentemente ed eschusivamente nociva. 2. Se, (fuando ancor non lo fosse, doveano in allora temersene gli stessi danui.

S. 9. In adempimento di si gelosa incombenza ci facemmo a raccogliere ed esaminare quella Specie, che tanto imponea pel mimero prodigioso de' suoi individui, non men che tutte le altre clie ci rinsci di trovare a quell'epoca ne'

rileva le contraddizioni fra lo Scufonio a l'Anonimo fiorentino, e dimostra gli errori di entrambi.

(:) Origine, propagazione e danni delle Iocuste. Operazioni praticate per la loro estirpazione nell' $\Lambda$ gro Romano ed in varj altriterritorj. Natura, " proprieti di tali insetti. Leggi, decisioni e divisione delle spese. Opera divisa in tre parti, di Luigi Doria romano membro di diverse Accademie. Il Tratcato del sig. Luigi Doria sulle cavalletle incomincia cosi: "Prenunziata da una fiesca alira soave sorgeva in oriente l'antrora vermiglia !! ec.,", 
contorni di Roma. E all'occhio non pur mudo che armato sottoponendone diversi esemplari, a parte a parte per via di rigorosa analisi comparativa ne javvisammo le differenze specificlie, e i caratteri si proprj clie conumi alle altre Specie. Nel I822 nacquero a primavera avanzata, e si accrebbero in varie parti senza arrecar danno sensibile: anche nel I 823 l' inverno fu lungo e freddo; ond'è che tardi, ma non già in minor copia, si svilupparono, fissando la loro dimora principalmente ne' territorj di Monticelli, Fiano, Leprignano, Nazzano, S. Oreste cc. Finalmente parve, che nel corrente anno si diffondessero nell'Italia meridionale, concentrandosi in varie parti del regno di Napoli, e nel limitrofo territorio pontificio di Benevento, ove diedero il guasto al frumento, al grano d'India e alle vigne (I). Nello scorso anno per comando dell'Emo Camerlengo di S. Chiesa avondo noi ripetute, verificate ed estese le nostre osservazioni, ci facciamo un dovere di pubblicarle, lusingandoci, che non sian per cssere affatto inutili alla risoluzione de' proposti quesiti.

\section{A R T I G O L O III.}

\section{Determinazione della Specie e descrizione zoologica.}

S. 10. LA specie conosciuta, cui somiglia piì che ad ogni altra la Cavalletta di cui si tratta, è l'Acrydium italicum ( $G$.locusta italica L.). Alcuni caratteri esterni sono commi ad entrambe; altri cui non si è atteso bastantemente son proprj della nostra: non osiamo per ora sopraccaricare di nuove Specie un Genere, che n'è già ricchissimo; solo ad oggetto di evitare la confusione e gli equivoci crediam necessario modificare la frase Specifica, ed argiungervi una estesa descrizione, onde sia a colpo d'occhio riconosciuta.

(1) La S. Consulta raccomaudo caldamente la distruzione delle ova : I periti disscro che le ova trovate non erano de'cosi detti bruchi ( cosi chiamansi dai mapolitani le cavalletle noeive V. la Mcm. del Sig. Gaetano De Lucretiis negli atti del R. Instit. di Napoli del 181 ! tom. 2. p. 233.), perchè le ova de'veri bruchi resistono ad ogni agente distruttore : noi abbiamo sperimentato, che i geli, e le pioggic dirotre e frequenti le decompongono. D'altronde, essendovi state le carallette in gran copia, non può supporsi, che non abbiano riprodotto la Ioro Specie. 
16

ACRYDIUH, Thorace tricarinato, segmentis tribus, alis basi roseis, apice lyralinis , (Fig. 1. n. 1.)

lar.

a. In thorace maculis utrinque tribus obscuris.

b. Thorace sublestaceo, carina medin subflava, nigro-marginata.

c. Thorace bilineato, elytris $2 a-$ "0-marginatis.

Ifabitat in Europa australi.

Longitudo foeminae lincar. circi1er 17.; maris 10.: gravida lin. 4 . lata.

Corpus a summo dorso ad cauclam subdeclive, subcarinatum; subtus planmm horizontale; ferrugineotestaceum, vel subflavescens fusco-maculatum, vel varium colore sriseo, virescente, subrubro. Siaejizls fusco-griseum, thorace obsenriore, abdomine cinereo, plus minusve diluto.

Canut (langum lin. 4. in foomina; 3. in mare) obtusum, verticale, subrugosum, grisco-flavescens.

rertex ovalis, excavatus, marsinatus.

Frons rectangularis, convexa.

Oculi grandes, laterales, bini, convexi, reniformes, punctis migris in lineas longitndinales digestis.

Stemmata tria: bina rotunda inter ocnlos et antennas: tertium ovale in inclio frontis.

Anternae in focm. longaelin. $5 . \frac{1}{3}$ in mare 4. $\frac{1}{2}$ ( $\left.\mathrm{rig} .3 .11 .5.\right)$, filiformes, subfulyne, corpore breviores, $e x$ is ad 24-articulis mobilibus: primus -longior el crassior; aiter gracilior, brevior : all octavum usque etiam breviores; luine duplo longiores.

Labium superins ( Fig.3. n.3.) manifestum, medio sulcrum, infe-
Acridio "Corsaletto con tre carene, c tre segmenti : le ali rosce alla base, scolorite e trasparenti nell' $\mathrm{Val}$. apice. ( Figg. 1. H. 1.)

a. Con tre macchie oscure da ambi i lati del torace.

b. Col corsaletto color di mattone, colla carena di mezzo giallastra, orlata di nero.

c. Con due linee sul corsaletto, c gli astucei orlati di giallo.

Abital'Europa anstrale.

La femmina è lunga circa $1 \%$. linee, il maschio 10.: gravida larga 4 .

Il corpo di sopra dalla sommita del dorso alla coda alquanto inclinato, e carenato: di sotto piano, orizzontale, color di mattone pesto, o olivastro bigio, che persele a color di ruggine, o lionato senro sparso di macchie ncre, o cenerognolo, o rossiccio sbiadato: per lo piil fosco grigio, col corsaletto piu scuro: coll addomine cencrognolo piu o meno dilavato.

Capo (lungo \&. linee nella femmina, 3. nel maschio) ottuso, verticale, un poco rugoso, tendente al grigio giallastro.

ll iertice ovalc, scavato, maxginato.

Ia fronte rettangolare, conressa.

Due occhi grandi, laterali, convessi, reniformi, con linee paralelle longitudinali formate da punti neri.

'Tre punti elevati, nitidi e lisci (occhi semplici, stemmata): due rotondi fra gli acchi e le antenue; il terzo ovale nel mezzo della fronte.

Le anterue (nella fommina lunghe 5. linee $\frac{1}{2}$; mel maschio $4 \cdot \frac{1}{2}$ ) ( Fig. 3 . n. -.) filiformi, di color lionato cliaro, più brevi del corpo, di diciotto a rentiquattro articoli mobili : il primo piu lungo: il secondo piu sottile e piubreve :fuo all'otlavo anche piu brevi ; gli ultimi piu lunglıi del doppio.

Labbro superiore (Fig. 3. n. 3.) evidente, solcato nel mezzo, inferior- 
rius convexmm, striis lineisque :ariis pxaralum, margine superivie incegro, inferiori semi-orbiculari, tmarginato.

Labium inferius (Fig. 3. num.f.) convexum, rhosum, sitco medio iranswerso, siblus bilobalum: palpi duo lateribus porrectis alluati, arlicnlis lribus, postremo longiore, subclaralo.

Haxilla (Fig. 3. 1.6. ) subcylinrrica, collvexa, corincer, dentibus wibus conicis, aculis, corneis.

Palpus lateriextremo adlacerens, c)lindricus, quinque-arliculatus, setosus, basi sinuosa, apjice trumGilo.

Galca formicata, coriacea, maxillas undigue oblegrans.

Mandibula ( Iig. 3. n. 5. ) cornea, erassa, apice nigro-violaceo, dentiuns $;$. vel 8 . inserlis, alternis; superiores cuspilati, infcriores spathiformes, altero remolo, obtuso, trilobato; altero subtriangulari.

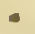

Thorax anticun annulare, latevibus dilatatis, depressis, obusissimis, earinis tribus laevibus, merlia acutiore, tolidem segmentis carinas intersecantibus; margine antico integro, postico appendiculato. Longit. infoemina lin. 3. $\frac{1}{2}$, in mare liv. 2.

Sternum ovale, extus convexum, intus concavum, processibus quatuor osseis in scapularum forman assurgrentibus: appencïcula ossea bifula mente convesso, seguato con varie stric e lince, col lembo saj)eriore intero, linforiore semi-orbiculato, smarginato.

Labbro inferiore ( $\mathrm{Fig}$. 3. n. 4.) conresso, rugosa, con un solco medio trasverso, diviso inferiomente in duc lubi: dai lati sporti in fuori produconsi due palpi di tre articoli: l'ultimo priu lungo, qnasi a modo di clava.

Lo due mascelle ( Fig. 3. n. 6.) scapenonsi al di dietro del labbro inferiorc, lunglue, cilindriche, inarcate, coriaee, con tre denti lunghi, conici, acuti, cornei.

Duc palpi cilindrici, di cinque articoli, sparsi di brevi e radi peluzzi, colla hase sinuosa, l'apice troncato: adcriscono alle estremitá laterali cstcrne delle nascelle.

Una nucmbrana (galea) coriaces, fatla a robta lecuopre per agni dore.

Due mandibole (Fig. 3.n.5.) dictro il labbro superiore, cornec, laterali, concare allindentro, nero-riolacec nell'apice, con 7.0 8.denti. I d'nti articolati reciprocamente : i quar tro superiori acuti, gl' inl'eriori rotondi in forrua di spatola: uno di questi piu intermo isolato, ottuso con tre tubercoli: un altro quasi triangolare.

Il torace anteriore, o corsaletto ì annulare, col disco quasi quadralo, che si prolunga verticalmente nei laci irregolarmente depressi, posteriormente rugoso, con tre line longitudinali, clevate, liscic, a manicra di carena, la media più aenta equidistante una linea e mezzo dalle laterali: tre incisure, o segmenti le traversano ad angolo retto: il margine anteriore senza incisure, curvo, lineare, posteriormente angoloso, per una piccola appendice connesso col torace posteriore, latcralmente ottusissimo. Lungo nelle femmine lin. $3 . \frac{1}{2}$, nel maschio lin. 2 .

Lo sterno nel suo insieme descrive un ovale convesso al di furi, concavo al di dentro: nella sua parte interna trovansi quattro appendicios- 
I 3

eminens e mellio sexmenti ossei, cmi primum par incumbir: prope basin alicrius paris ammulus membranula tectus.

In antica parte sterni apophisis c) lindrica, crnstacea, setosa, verticalitcr descendens, in papillant desinens, segmento osseo inmixa, papillaris nuncupanda.

El) lra (lincas tres lata, undecim longa) curpore wix longiora, cestaceo-nebulosa, maculis nigris irreguiaribus latis, Mexilia, coriacca, alas Icgentia, inclinata, margine interiore altiori, apice rotundata; nervis longitulinalibus, zenisque transversis reticulata.

Alae membrinacene, liasi roseae (1), mervosae, reticulatae, con-

(1) In roseo alarum disco habitat saele ruaedam Acari species microscopica, (Fig. 5. e 6.) cui idem roseus color : nobus Leptus A. italici. Huie corpus orale, mulle, antice in caput tululosum porrectum desinens : pa!pi conicj, basis sec a modo di scapole: il primo pajo auteriore deriva da una linea rilevata ossea semilunare, dal mezzo della quale sorge nu'apofisi : somiglia l'osso poide umano colle sue corna: un anello osseo coperto da una nembrana trovasi alla base del secondo pajo posteriore. Queste appendici interne cor' lispondono ad altrettante incisure esteriori, ele dividono lo sterno in sette pezzi ineguali : allanello osses corrisponde nua prominenza, intorno alla quale vi souo dne incisure semilunari. Questa fabbrica serve agli attacchi delle quattro ultime gambe, e a quelli de loru muscoli estensori e flessori.

Dalla parte auteriore dillo sterno scende rerticalmente un' apofisi cilindrica, crostacea, rohusta, sparsa di peli, stabilita s'pra un arco osseo interno: serve di apporgio all insetto per ispiceare il salto : per la figura delia sua estremita le daremo il nome di papillare.

Crli astucei, o elitre (Fig. 1. n.2.) (larghe tre linee, undici lunghe) sono color di mattone foseo, sparse di macchic nere larghe, irregolari, flessibili, coriaces, orizzontali, $m$ poco piir lnnghe del corpo, rotontle nellapice, e cunprono le ali, avendo il luro margine interno piu elevato. S'impiantano sulto il margine posteriure del disco dorsale nei punti clue colrispondono alle carene laterali: hanno le costole longitudinali molto rilevate da ambe le superficie, ed altre piir leggiere che lis traversano irregolarmente, formandone una vaghlissima rete.

Le ali sono tinte di un rivacissimo color di rosa (1) in entramlse le super-

(1) Sul disco roseo delle ali alita sovente ceria specie di Acaro microscopico, (Fig. 5. e 6.) che nutresi forse del principia colorante dell'ala, perché è ancla' esso dello stesso colore. Ha il corizo avale, molle : la parie anteriore 
colores, sensim slitutiores, apice nudac, hyalinae.

Pedes amtici longi lin. 6., medii 7. , postici saliatorii 10. : robula lata, convexa, inferius cuarctata, cum corpore laxe articulata.

Femur in anlicis binis paribus longum, angulatum, depressum, facie inferiori excavainu, marginibus rejlexis.

Femur posticum, clawatum, quadrilnterum, latum, crassum, antice puncratm: facies superior carinats, inferior canaliculata: e lateralibus (striis transversis, parallelis, subrotundis, margine exser- ficie, che va gradatamente sfunando dalla base verso i lembi csteriori, finchi: si perde e lascia le estremita trásparenti, senza colore, reticolate, colle costole negre e spesse: nascono all'infuori e al disotto degli astucei quasi mezza linea : dove queste si attaccano vi si distinguono le inmestaturc con dircrsi pertugi, per dove passano i loro muscoli estensori: sono anch' esse reticulate cla costole trasverse e longitudinali : presso la loro base vina una macchia bianca reniforme.

I piedi anteriori lunghi sei lince, i medj 7. , i posteriori atti al salto 10.: la rotula larga, convessa, che si muove liberamente entro una cavità articolare, e si ristringe nel punto dell' articolazione col trocantere.

11 femore uclle due paja antcriori luago, angoloso, un poco depresso, accanalato nella faccia iuferiore co' margini ripiegati a modo di cticchiajo per ricever la tibia.

Il feruore posteriore (Fis. 3. n. 8.) clavato alla base, largo, grosso, punteggiato in avanti, diviso in quattro faceic; la superiore carenata, l'inferiore accanalata per la flessione della tibia: delle due face laterali (linea- articulo crassiore: pedes sex longiores in mare ( $F_{i g} .5$. ) In singulis alis utrinsque sexns numquam plus quam binos invcuimus : lente movetur: discum roseum non praeterit: Acrid. vitae interdum superest per integram diem. Haec Species pertinet ad Solenostomos parasitos (Latreille tom. 3. p. 68.) et proprie ad Genus Leptus. Haec nohis ope praestantissimi microscopii claris. professoris Amici observare datum est. terminata da un tubo ottuso, sporgente all' infuori: i palpi conici, il cui maggior articolo è quello della base: sei zampe piu lunghe nel maschio (Fig. 5.) che nella femmina. (Fig. 6.) Questi Specie sembra appartenere al Genere Leptus della Famiglia Ricini, dellOrdine solcnostomi parassiti di Latreille. (tom.3. p. 68.) Trovasi promiscuamente in tutt' $i$ tempi, in tutti $i$ sessi, ma non in tutt $i$ gl'individui; a non mai in numero maggior al due in ogni ala : si nuove lentamente, serzza partirsi mai dal disco colorato delle ali: perisce insieme coll' acrydium, ma talvolta gli sopravvive per qualche giorno. Non essendosi finora ritrouato che nell'acrylium italicum in istato perfetto, potrebbe denominarsi , Leptus Acrydii italici . Di queste osservazioni siam delitori al prezioso microscopio lel chiaris. professorc Anici. 
10 circumscriptis), interna facies concava, sanguinca, maculis nigris tribus, binis semilunaribus articulavibus, cxlenna convexa.

Tibiae anticae et mediae fere prismaticas, inferne duplici denlimu ( ex $7 \cdot$ ad $9 \cdot$ ) ordine serratae.

Tibia postica undique rosea, qurdrilatera, superne servala, dentibus aculis, obliqnis, apice nigris a 20 ad 22; quatuor articalum tibiae cum tarso circumeunibus.

Tarsus triarticulatus in unguiculos binos desinens, arcualos, rigidos, opposilos.

Tarsus posticus subtus callosus: prinus articulus crassior, callo inregro papillari; medius brevior, calto sulcalo: postremus gracilior, calto cunciformi inter ungues oppositos.

Abulomen suöconicum, annulis integris imbricalis: incisurae lineares arl latern binae.

Onot abslominis annuli, tot utrinque stigmata.

Al latera primi segmenti dorsait is duo lata foramina ovalia, membrana pelluciela speculiformi obiecta.

Focminae segmenta dorsalia subcarinata 8.; ventraliu 6. longiora: mari utrinque 8., prima dorsalia '́. carinata, lonsiora.

Extremi annuli pars dorsalis in mare hemisplierica, arl latera complanata, portecta, arliculata cum lamella triangulari, longimulinaliter. sulcala, vertice bifido, aculo, setisguc rigido: sub lamina anus. te da strie trasverse, paralclle, quasi rotonde, circoscritte da un margine rilevato), l'interna concara, color di sangue, con tee macchic negre, due delle quaii senuilunari ai lati dell'articolazione; l'esterna convessa.

Le tibic anterior'i c medie quasi prismatiche, armate di doppin nreline di denti inferiomente (da sette a nove in ciascun ordine).

La tiluia postcriore color di rosa, con quattro faccic, smperiormente deutata a modo di sega con renti a vontidue denti, acuti, obliqui, siegri in punta: quattro circondano l'articolazione della tilia col tarso.

I tarsi anteriori e medj di tre articoli: l'ultimo armato di due unghie inarcate, rigide, oppostc.

Il tarso posteriore inferiormente calloso: il primo articolo is it piit grosso, ed ha il callo in forma di papilla; il medio is il piin Jreve, col callo solcato; l'ultimo piin sottile con un callo cuncifurme frapposto alle unghie.

L'addomine quasi conico con anclli interi, embricati, connessi per mezzo di una membrana: lnngo i lati due inéjsure lincari, le quali non tagliano gli anclli.

Presso la detta incisura v'ha una fila di punti negri appena impressi ( tanti da ogni lato, per quanti sono i seguenti delladdomine ): sono questi gli stigmi, o orificj de'condot ti per la respirazione.

Sotto il dorso ai lati del primo segmento si aprono due larghi forami ovali ricoperti da una membrana pellucida in forma di specchio.

La femmina ha otto segmenti dorsali leggermcnie carenati, sci ventrali pin lunghi: il maschio otto, tauto nel dorso che nelladdomine: i primi quattro dorsali carenati, piu lunghi.

Nel rnaschio la parte superiore dell" ultimo anello è emisferica: si prolunga e si appiana secndento pe"lati, e forma duc ali sporgeuti allinfuori col nargine rotondo: si connette con una lamina triangolare rugosa, solcata longitudinalmente rel mezzo, e spugno- 
Corruicula bina, horizontalia, ex lateribus basis lammae orta, alba, mbolimdrica, arcuata (tres lin. lunsa, rnediam lata) tnberculo nistron marginali, interiore, prope basin, extremitatibus tridentatis : inferior dens diaphanus, longior, mollior; medius acnus, niger.

Membrana dorsalis semiconica, r"Igosa, contractilis, ad basin aperta., ultra zerticem laminae triansularis una cum extrema lamella rentrali genitalia obtegens, conum integrum efficiens, vertice in caltdam rectam acuminatam producto.

Penis conus truncatus, sulco antico longitudinali, basi lenticulis nigris conspersa, membranula laxa, crispa, replicata, induta.

Corpora reniformia duo, slandulosa, rubescentia ad latera basis.

Foliola quatuor cornea, sub-riigra, ovalia, sulcata, retractilia, floris calicem aemulantia, planum a coni sectione efformatum circumeuntia.

Extremus foeminae annulus longior, mgosus, in partu evolvendus. Segmenti par's dorsalis in tres laminas semicirculares imbricatas decomponenda. Fixtremae laminae jungitur membiana triangularis, sponsiosa, subnigra, punctulata, curvilinea, erectilis, sulco verticali honizontalcn secante. sa ne' Jati: il rertice di questa !amina ¿̀ aguzzo, foreuto, cou brevi " robuste setole: l'ano si apre al d: diefro di questa.

Dagli angoli della base di detra lamina uascono due lunghe appendiei bianche, orizzontali, fluasi cilinuliche, (luaghe tre linee, largalde mezza) eon un tubcrcolo nero nel margine iusterno viciuo alla base, e tre désti in eiascuna estremiti jibera: l' inferiore trasparente, piin lungo e men cluro; il medio aculo e nero.

Al di là del vertsee della lamina triangolare v"lia una membrana semiconica, ragosa, contrattile, che mita ad altra nembrana semiconica ventrale chiude l'estremita del corpo con un intero cono, i] cui vertice si prolunga is una specie di coda retta ed acuminata ; tal membrana è aperta alla base, per cui ripiegandosi sopra se stessa, senopre una vasta e silluosa cavita elıe si profonda nei lati.

Nel piano di questa cavita é radicato il penc, clìe un cono troncato sparso dicorpicini lenticolari nelastri, con un solco longitudinale anteriore : un terzo del cono dalla base verso l'apice è rivestito da una membrana increspata.

Presso i lati tondeggiano due corpi rossastri in forma di reni, e come ghiandolosi.

Intorno al piano formato dalla sezione del cono sorgono quattro foglioline negre, comee, ovali, solcate, retrattili, nou molto dissimili dal caliee di un fiore.

L'ultimo anello del corpo della femmina è più lungo degli altri, rugoso, estensibile, atto a svolgersi cd allungarsi uel parto. Il segmento dorsale di questo circolo é diviso in due membri: il ṇimo si può decomporre in tre successive lamine scuicircolari embricate, co'margini angolari ottusissimi; il secondo rappresenta un triangolo eurvilinco, la cui base semicircolare si articola mobilmente a ecruieza co't? ultina delle descritte lamine: dal suo vertice ch'è libero scende una stria verticale fino alla base, tagliata ad 
Intima lamellae triansularis facies in binas membranulas griseas horizontales reflexas porrecta : ex his cavitas flexwosa, in cujus imo vulpa.

Segmentum vantrale in binos arcus semilunares desinens, quos inter aculeus corncus, triangularis.

Appendices 4. horizontales, subcylindricae, parallelae, ulere cauclam prodeuntes, extus concavae, favescentes, ovales, marginibns prominnlis nigris, apice adunco, superne atque antice refle.20 in modum ungulae Rnninantium; in aculeum colligendac, fossoriae nuncnpandae. Dor'sales majores segmentis dorsalibus innixae; ventrales minores, dorsalium basi incumbentes, apice opposito, circulariter prope ungulam sulcalae.

Utriusque sexus genitalia pilis ornantur plus minusve derssis, brevibus, hispidis.

Larva hexapoda, agilis, aptera. Nimpina agilis, alarmu rudimentis, corpore brevioribus. angolo retto da una incisura trasrersa presso il terzo inferiore dei lati del predetto triangolo: la porzion d'area compresa fra il vertice e la linca trasversa, è spugnosa, ucrastia e sparsa di sottilissimi forellini.

Sollevandone il vertice libero si vede, che dal mezzo della sua superficie postcriore intcrna derivano dne produzioni nembranose grigic orlate di biñnco, comargini sinnosi e rotondi; e queste prolungandosi orizzontalmente si ripiegano, e vengon quasi a contatto fra loro. Da tal manicera di tranczzo risulta fra l'area del triangolo, e le predette nembranc una cavitá flessuosa, nel cui fonclo si apre l'ano, che fa anche l'officio di vulva.

L'altra estremità inferiore del col$\mathrm{po}^{\prime}$ (il segmento ventrale) termina con due areli scmilunari, fra i quali uasec un pungiglione cornco acutissimo, triangolare.

Intorno, e al di là dell'apice della coda sporgono quattro lunghe e grosse appendici orizzontali, ciliudriche, paralelle (le dorsali maggiori delle ventrali): dilatansi ambe le paja in una spccie di scarpa giallastra ovale, co'margini rilevati neri, concava all" esterno, collapice adunco, c ripiegato per di sopra, c in avanti; simili in parte allo zoccolo degli animali ruminauti. Poggiano le dorsali sopra due pezzi in forma di lancia solidamente impiantati intorno ai segmenti: alla base di queste si articolano le ventrali piir piccole, men concave, c mcno adunche, dirette iu senso opposto alle prime, divise presso lo zoccolo da un solco circolare : questc appendici insieme rimite compongono un robusto pungiglione; e poichè la cavalletta si serve di tali appendici per iscavare la terra, crediamo clue possa loro competere il nome di organi scavatoj.

Tuttc le parti esterne de' genitali di entrambi i sessi sono munite di pcli piu o men folti ispidi e brevi.

La larva agile, con sei piedi, scnzali.

La ninfa agile coi dudimeati delle ali più brevi dcl corpo. 
Digestione, respirazione, sistema nervoso.

S. Ir. Le cavallette hanno ambedue le labbra scoperte e a mutuo contatto fra loro. Dietro il labbro superiore trovansi le due mandibole laterali, robuste, dentate. Al labbro inferiore sono attaccate due appendici filiformi (palpi labiales ) composte di molte articolazioni mobili, che servono al tatto, o ad avvicinare l'alimento alla bocca, o come altri vogliono alla loco-mozione. Rovesciando il lablyro inferiore appariscono le due mascelle-fortemente dentate e munite di altri due palpi. Fra le due mascelle v'la una nembra11 cilindrica ottusa, vescicolare, inarticolata c couvessa (galea ), che a maniera di scudo si sta loro dinnanzi a difesa: questa parte nel sistema di Fabricius forma il carattere distintivo della loro bocca.

S. 12. Fra i due palpi mascellari esiste la così detta lingua ( forse per l'analogia colla parte che sostiene la lingua degli uccelli) che nelle locuste è carnosa e libera in punta: lia due frastagliature lunghe e rotonde nei lembi esterni ed altrettante brevi ed aguzze nel mezzo : al di sopra di queste si apre il faringe. Gli entomologi hanno accordato lo stesso nome di lingrua anche al tubo spirale, con cui le farfalle attraggono $\mathrm{i}$ fluidi, non clie ad altri organi diversi per la situazione, per la conformazione e per gli usi. La cute che riveste la lingua è più sottile e più morbida: il di sotto della cavità della bocca ov'è contenuta dilatasi a modo di ampolla, donde si può arguire, clıe formi gran parte dell'orgrano del gusto, negli ortopteri assai sviluppato ed evidente.

S. ı3. La bocca degli acridj e delle loczsste è bagnata da certa specie di saliva giallo-verdastra, or salata, ora iısipida, or caustica, la quale abbonda principalmente nel tempo della masticazione, e si mesce col cibo. La locusta verrucivora vien cosi distinta dal potere che ha la di lei saliva di corrodere radicalniente i porri e le vernche nella cute dell' nomo. Tal fluido per quanto sembra è separato da due lunghi vasi spongosi, simili agli altri organi separatori degl' insetti, come schopri l'acutissimo Lyonet nel notomizzare la 


\section{$2-\frac{1}{6}$}

sua larra del salcio. Il canal diresivo is sempre egnale in tutti gli stati della loro incompleta metanorfosi : l'esofauso poco sotto al furinge dilatasi in una specie di goz\%o di colombo, la cui interna membrana è liscia ed increspata longitudinalmente : ne' Generi Linneani Gryllus e Blatta questo primo ventricolo è piu ampio che negl' altri ortopteri. Segue un secondo stomaco, o ventriglio, quasi rotondo, muscoloso, armato internamente di varj ordini longitudinali di folte e minute scaglie embricate, col margine libcro rivolto verso il primo stomaco. Intorno all' oriticio posteriore di questo v'ha un certo numero d'appendici piloriche, come quelle de' pesci, dette dal Redi conserve pancreatiche : il Genere locusta ne la lue, lunghe ed ampie, che fur già descritte come due stomachi, ond'è che si disse aver elleno ruattro ventricoli cone i Puminanti : nel Genere Acrydium si contano cincrne appendici. Le cavallette pertanto , o abbiasi in vista lo sviluppo dell' organo del gusto, o il numero degli stomachi, o la qualiti del cibo, o forse anche il creduto potere di farlo risalire alla bocca, devono esser considerate come i ruminanti fra $g l^{\prime}$ insetti.

S. I4. Mancando agl' insetti la vera circolazione, le secrezioni non si fanno per via di alcuna ghiandola conglomerata : tutto l'apparato secretorio, che riguarda il canale degli alimenti, si ridnce ad alcuni tubi spongosi sottilissimi, ondeggianti nel fluido che bagna la cavita dell' addomine : assorbon questi per forza organica elettiva del loro tessuto gli elementi della bile, e ne prendono il colore. I condotti biliari son molti e brevi nelle locnste : circondano l"intestino poco lungi dall'ano, riunisconsi in un canal comune e sboccano entro la parte media della cavità intestinale. L'intestino è sostenuto dalle sole tracliee, poiche non vi sono nè vasi, nè mesenterio, nè tessuto celluloso; ond' ̀̀ che una locusta immersa nell' acqua coll' addomiue aperto, galleggia per lo svolgimento delle pieghe intestinali, e per l'aria che entro le trachee si racchinde. Supplisce in qualche modo al peritoneo una delicata membrana, che involge le viscere addominali, ed è sostenuta dagli anelli della cute e dai loro muscoli. La nutrizione si fa per un assorbimento immediato: il chilo feltra a traverso le pareti dell' intestino, e cola uniformemente in tutte le parti interne, che sono a tal uopo comunicanti fra loro, non essendovi alcun diafram- 
ma chie le divida : ogni parte attrae la porzione clue le conviene.

S. 15. Il preteso cuore delle cavallette, come quello di tutti gl'insetti, è un canal membranoso, che nasce presso il capo, scorre lumgo il dorso e termina all'ano; formato di piccole ampolle senz" aperture, munito all" esterno di molti fascetti inuscolari trasversi, e ripieno di un fluido viscoso e griallastro, il quale misto all'acqua s'iutorbida e contiene un gran numero di globetti trasparenti, infinitamente piccoli : disseccato somiglia la gomma. Questo condotto, pel fluido clıe vi si racchiude, pe' moti alternativi, regolari e continui di contrazione e dilatazione, propor temperatura, e per 1'analogia colla posizione del cuore de' Crostacei e de" Mollusclii che risiede sul dorso, fu creduto da Malpighi, (che fu il primo a scuoprirlo nella larva della fillena del Gelso, e ne osservò i movimenti nelle locuste ) essere il cuore degl'insetti. Swammerlam ci assicura, che le injezioni colorate spinte entro il canal dorsale delle cavallette passano pe' vasi latcrali comunicanti con quello; na poiclıè vani riuscirono gli stessi tentativi al pazientissimo Lyonet, all' incomparabile Cuvier e ad altri zootomi di sommo nome, convien dire che non esiste la pretesa comunicazione, e che il canale di cui si tratta è chiuso per ogni dove. Oltre le fibre muscolari molte centinaja di broncli c di nervi e di rami cellulosi recansi a cuesto tubo : il Malpighi vide pel primo nelle cavallette il tessuto adiposo ripieno di pinguedine intorno allo stesso canale e gli attribui il medesimo uso dell'omento; poichè aduncue non vi si scorgono nè aperture, nè vasi, nè moto intestino eü attivo nel flujdo, forza è concludere, che i moti di contrazione dipcndono esclusivamente dall' azione de' muscoli estrinseci. Cosa ̀̀. egli pertanto cotesto canale? Un organo secretorio simile a tutti gl'altri clie trovansi nelía Classe degl'insetti? Ma qual'è. l'umor segregato, e a qual uso?

S. I6. La respirazione ha per iscopo il contatto dell'aria col sangue per depurarlo: ove esiste circolazione, il sangue. va a mescersi coll'aria : ove non è circolo, l'aria va in traccia del sangue. Perciò negl' insetti v'ha ai lati dell' addomine uno, o piu. ordini di piccole lamine scagliose·, aperte nel mezzo, guamite di valvole memblanose, che ne custodisco-. no $1^{\prime}$ ingresso: son queste ( stigmata) gli orificj de' condotti. 
26

aerei ( fistulae, tracheae), che metton foce ai due principali tronchi cilindrici, paralelli, longitudinali, donde spiccansi infiniti rami, che a modo di raggi divergono dal centro. L'aria atmosferica per forza di pressione s'introdnce ne' stigmi, s'inoltra ne' canali aerei : tutto trascorre ed invade il sistema tracheale : si combina col sangne, e ne determina la vital combustione. La più parte delle trachee è composta di tre membrane: la media consiste in una linea spirale, elastica, di lncentezza metallica, che sostiene le pareti de'vasi, e da loro la convenicnte flessibilità ed il potere di raccocciarsi e distendersi, scnza che se ne otturi la cavità : altre trachee mancano della spirale e dilatansi di spazio in ispazio alla maniera di vesciche, o di ampolle. L' aria che ha servito alla respirazione, esce ( tal'è l'opinione di Reaumur e di Degecr) per alcmi sottilissimi pori, che apronsi sulla cnte. L'illustre Vanquelin la analizzato l'aria espirata dalla Locilsta viridissima: immerse eghi un maschio di questa Specie in un atmosfera di sei pollici cubici di gas ossigeno: i moti di respirazione, ch'erano nell'insetto da 50 fino a 60 per minuto, si aumentarono di un dodicesimo divenendo irregolari e interrotti: l'insetto nel termine di dieciotto ore peri totalmente, senzachè il vapore dell'ammoniaca potesse ravvivarlo. L'aria residuale erasi diminuita in volume di cinque centesimi : non ispegneva la candela, ma intorbidava l'acqua di calce. Altro simile insetto immerso in dieciotto pollici cubici d'aria comune ha vissuto trentasei ore: il di hii respiro non soffiri alterazione, nè intermittenza : l'aria residnale non bastava ad alimentare la fiamma di una candela, ed era perciò più viziata della prima. Finalmente un'altra locusta introdotta in $17 n^{\prime}$ atmosfera di gas idrogeno solforato morì all' istante e totalmente. Ciò dimosira, che anche le locuste e tutti probabilmente gl'insetti, si appropriano l' ossigeno, ed espirano il gas acido carbonico : che la quantità di ossigeno sufficiente a mantenere la combustione di una candela uon lo è per la vita di un' insetto. Ma il calorico che si svolge in questo singolar modo di respirazione non innalza sensibilmente la temperatura del corpo dell' insetto al di sopra di quella dell'atmosfera; nè più elevata è per certo quella del fluido contenuto entro il tubo dorsale ; donde arguisce Brogniart, che negl' insetti la quantità di calorico resa libera nel combinarsi dell'ossigeno col chilo, è pom :co o nulla sensibile. 
S. I 7. I due lobi componenti il cervello della locusta virisissima si trovano sopra l'esofago: la loro sommità si prolinga nei nervi ottici, che si portano agl'ocehj composti. Dal dinnanzi dei lobi nascono due aleri nervi piramidali : fra questi v' ha un piccol ganglio, ch? è il nervo ricorrente, e siegue il canal digestivo : dalle estremità dei lobi derivano alcune fila nervose, che perdonsi nelle labbra e nelle mascelle. Un poco al di sotto e al di dietro del cervello hanno origine due cordoni midollari, che formano il primo ganglio sotto l'esofago, cui sovrasta una lamina cornea giallastra a modo di ponte. Partono da questo primo ganglio due cordoni, che nel mezzo del torace riuniti compongono il secondo ganglio, donde i nervi pel moto delle zampe anteriori : Il terzo ganglio deriva da due fila del secondo; trovasi fra le due gambe intermedie, e getta rami pel moto di queste e delle ali : Il quarto ganglio è prodotto dalla riunione di due cordoni del terzo, e trovasi fra le due ultime gambe. Sorgon da questo due cordoni aderenti e rimiti in un solo. nervo, il quale si asconde in una specie di doccia scavata nella lamina triangolare, che dà attacco ai muscoli delle zampe. I seï altri gangli trovansi nell'addomine : cincue altri simili, vicini ed equidistanti tra loro, concatenati da due cordoni nervosi : ogni ganglio dà due paja di nervi ai muscoli di nuo degli anelli ventrali. L'nltimo, ossia il decimo ganglio è per la metà più grosso degl' altri cinque : si dirama ne' genitali per quattro paja di fila..

S. I8. La vista e l'ndito sono i sensi più perfetti nell' Ordine degli Ortopteri : trovansi in tutti tre-occhi semplici frontali, e due laterali composti. Sembra (direbbe un poeta ) che la mano Creatrice ne lanciasse alla rinfusa sul capo di questi viventi : che alcuni isolati e divisi si spargessero irregolarmente e s'imprimessero sulla loro fronte :- altri poi rimitisi in due gruppi s'appiccassero simmetricanente ai lati del capo. La comea degli occlii composti è suddivisa in nua gran cuantità di faccette esagone, convesse' al di fiori, concave al di dentro, e separate da solchi guarniti di finissimi peli, più spesse nel mezzo ed intonacate nell' interno da una vernice oscura, che nun lascia adito alla lnce. Fra la vernice e ciascuna faccia della cornea s'insinua perpendicolarmente un filamento biancastro prismatico: a questo. gruppo: di fila serve di base una membrana cellulosa para-- 
28

lella alla stessa cornea, il cui color nero è inerente al tessuto, e rappresenta la coroide. Al di là di questa v'ha una espansione membranosa del nervo ottico, che rappresenta la retina. Questa membrana diramasi nelle fila che traversano la coroide, e s'impiantano nella cornea. Che la coroide sia forata si deduce per l'analogia cogli oechi de' grandi crostacei, ne' quali vedonsi oltre $\mathrm{i}$ forami anche $\mathrm{i}$ prolunganenti degli orificj di questi : comunque sia, certa cosa $\dot{e}$, che il semplice esterior contatto della luce basta negl' insetti al fenomeno della visione. (1)

S. I9. L'organo dell' udito della locusta viridissima esaminato dall' illustre Comparetti trovasi nelle parti laterali posteriori del maggior ganglio rappresentante il cervello: consiste in un piccolo sacco allungato, entro il quale vi son de' canali pellucidi, curvilinei, tortuosi, che si ripiegano su loro stessi; ed a questi miochiansi delle fila bianche con una mucosità nervosa. Commuque incerta sia la sede di quest'organo, può sempre arguirsene l'esistenza dallo stridore o ronzio, e dalle parti destinate a quest' uso nelle Specie che non vivono in società, affinchè le fenmine che trovansi lungi dai maschi ne odano la chiamata, ed accorrano e si riuniscano per la riproduzione. Questo suono acnto e stridulo, che tramandano alcune specie di locuste e di cavallette deriva dallo strefinamento o degli astucci fra loro, o dall' azione ( non mai simultanea, ina alternativa) de'femori o delle tibie contro gli astucci, o finalmente da due aperture ai lati del ventre. A tal nopo la sostanza degli astucci ne' margini interni, e più sovente nel lato interno della base, non lungi dallo scurletto, è vitrea, trasparente, in forma di specchio, elastica e crepitante. Altri poi hanno in ciascun lato dell'addomine una profonda apertura, il cui contorno è ovale: una lamina scagliosa coperta da una membrana striata co'margini guarniti di finissimi peli, forma in parte la predetta apertura, e lascia uno spazio semilunare. Una pellicola bianca, tesa e lucente occupa la capacità del fondo: se questa tolgasi, vi si scuopre sotto una gran cavitì: uı forametto ovale apparisce nel lato dell'apertura più prossinı

(1.) De Serres memoire stu les yeux composès, et lisses des ortzoptires. ( Journal de Physique de Mr. La Mètherie an 1809. cahier 4. 
al capo: quest' organo manca all' acrydum italicum e al migratorium.

S. 20. L'organo del gusto delle cavallette esiste forse nella lingua e ne'palpi, i quali a dir vero lamno un tegumento coriaceo insensibile, ma l'ultimo loro articolo è rivestito da una membrana molle e vescicolosa. Negl' insetti in generale suppliscono i palpi alla brevità delle mascelle e delle altre parti della bocca; ma nelle cavallette, le mascelle, le mandibole, i palpi, la lingua, il canal digestivo e gli organi della saliva, che in gran copia sgocciala loro dalla bocca nel tempo in cui abbisognano di nutrimento ; son tutte parti assai hene sviluppate e perfette. Per lo che, se gl'insetti sono dotati di questo senso, convien dire che le cavallette lo siano in preferenza di ogni altro, come $i$ runinanti fra i mammiferi.

S. 2r. La più parte de' zoologi tiene per fermo, che negli ortopteri esista l'organo dell'odorato. Dumeril lo suppone nell' ingresso ai condotti dell'aria presso i stigmi, ciocchè era stato già detto da Baster; è più verosimil peró l'opinar con Latreille che risieda nelle antenne

I. Perchè la sensazione dell' odorato si ha dal contatto di una membrana nervosa coll'aria impregnata di molecole odorifere : le antenne, essendo ricche di nervi, possono essere organo dell'olfatto.

2. Perchè i nervi delle antenne essendo internamente vuoti differiscono essenzialmente da tutti gli altri.

3. Perchè i maschi (in certi Generi, non però nelle cavallette) hanno le antenne più lunghe delle femmine.

4. Perchè le antenne sono più lunghe in quelli, che nutronsi di corpi organici corrotti.

5. Percliè mancano, o sono appena abbozzate negl'insetti rapaoi : i rapaci sedentarj, come i ragni, non ne lianno affatto.

6. Perchè togliendo loro le antenne s'istupidiscono,e perdon le traccie dell'alimento e dell'asilo.

Qual sia e dove sia l'organo del tatto è cosa tuttor problematica. La cute degli ortopteri è flessibile, ma non già molle o sottile abbastanza per essere applicata in più punti dello stesso corpo, ed acquistarne le sensazioni delle qualiti. 
Generazione, nascita, metamorfosi e morte.

S. 22. $\Gamma_{\mathrm{RA}}$ gli organi di secrezione possono anche aver luogo i genitali interni delle cavallette. Oltre le parti esterne, delle quali si disse all'art.III., aprendo ai maschi l'addomine, si trovano $\mathrm{i}$ testicoli, il canal deferente e le vesciche seminali. I testicoli sono gruppi di brevi e piccoli vasi intralciati in guisa, che formano una maniera di spazzola: sono involti in un muco giallastro, e traversati da rami tracheali. Il loro canal deferente ripiegasi in epididimo; e poco prima di rimirsi al suo corrispondente riceve due gruppi di vescichette da ogni lato : l'un pajo ne contiene più di sessanta, l'altro più di duecento : questi quattro gruppi riempiono più della metà dell'addomine . Nel punto di rimnione de' due condotti vi sono due altre vescichette ovali..Le ovaja delle fenmine consistono in ma trentina di tubetti conici per ogni lato, di cui il muco e le trachee compongono due masse ovali : ciascun gruppo si continua con un canal comune ch'è l' ovidutto, nel quale si versa un'umor" proprio ad impaniare le ova e a formarne il guscio. Agli ovidutti riuniti, pria che sbocchino nella vulva, si aggiungono una vescica ed un lungo vaso: le ova piùr grosse son le piì prossime ad entrare dal tubo nell' ovidutto:

S. 23. Il pieno svolgimento delle elitre e delle ali, che d'ordinario avviene nel mese di Giugno, indica nelle cavallette lo stato di perfezione: riavutesi dalla breve asfisia di due o tre ore, che soffiono nel compiere la lormetamorfosi, dilungan le ali incartocciate e ristrette, e provansi al volo:ne' primi voli non si scostano gran fatto da terra; ma poco dopo sollevansi a grandi altezze, e in istuoli si folti, che a modo di fosche nubi ne ascondono l'aspetto del sole: gettansi allora sulle terre coltivate, e danno il guasto ad ogni maniera di vegetabili: tutto fino a terra rodono e bruciano colla saliva e co'denti : i più ricchi e fertili campi in poco d'ora diventan deserti nudi ed oscuri, come se vi si fosse appiccato il fuoco. Se in questo fatal periodo della vita la spiga ancor biondeggia su i campi, è vana ogni lnsinga di mietere : ne troncano talvolta i nodi articolari e la fan cadere a terra ;. 
talvolta tutto divorano e foglie e steli e spighe e fin le reste pungenti. La durata di quest' epoca desolatrice è di un mese circa; e reca sorpresa, come vivendo esse in societil nel fior della vita, in istato di perfezione in quanto agli organi riproduttori, e ne'più caldi giomi d'estate, non risentano per si lungo tempo eccitamento alla venere. Tale indifferenza per la riproduzione comincia regolarmente a cessare ne' primi giorni di Agosto : i maschi per esuberanza di alimento non più bisognosi di soddisfare alle funzioni conservatrici dell'individuo, dispongonsi a quelle del sesso. In quest' epoca di vigor giovanile la forza riproduttrice delle membra è in realtà prodigiosa : attesta l'immortal Redi, che spiccando loro il capo dal busto van brancolando vivacemente ancor lungo tempo; e riesce talvolta di rimnestarlo collo stesso viscoso umore, che sgocciola dalla medesima attaccatura del capo, come già del favoloso Orrilo cantò l'epico di Ferrara:

Che se tagliata o mano o gamba gli era,

La rappiccava che parea di cera.

S. 24. I maschi delle cavallette che vivon riunite in società non han bisogno di farsi sentire da lungi $(\mathbb{S}$. 3. ), come l'acrydium stridulum, caeruleum, caerulescens etc.: decresce e si spegne la loro ingordigia, in ragion che si accende l'amor della specie : i maschi importuni ed audaci si danno a vezzeggiare le loro femmine, che sulle prime mostransi schive e ritrose : $s$ ' innamoran quindi, cedono ai loro assalti, e prestansi all'accoppiamento. Il maschio recasi d'un salto sul dorso della femmina; e stringendola co' quattro piedi anteriori ne trae a se il ventre con una delle zampe deretane, e lo dilunga e lo afferra comprimendolo fra le sue morse (art. 3.) colle quali si tien fermo, durante la copnla, sul dorso della femmina e si lascia trasportare sulle ali di quella; quindi ripiega per di sotto la parte dorsale dell'ultimo anello : solleva l'ultimo pajo di ganıe, abbassa la membrana che cuopre la base del cono troncato rappresensante l'asta maschile (art.3.), e dispiega entro la vulva, per vellicarne le fredde pareti, 'le cinque foglioline, che sorgon d'intorno al piano della sezione del cono. La femmina allora apre e distende i suoi organi scavatoj (art.3.) che muovonsi orizzontalmente dal di fuori al di dentro; e alla sveltezza di tal movimento contribuisce l'elasticità e rugosità delle membrane, che si frappongono tra questi corpi; in tal positura si 
stan per sette, otto o dieci ore entrambi conginnti immenori di lor sicurezza; poichè sorpresi non si dividono all'istante :non fuggon che tardi, ed è facile il farne presa. La femmina resa feconda s'inpigrisce; debole e grave u'è il salto ed il ro1o. Nell'approssimarsi al parto, (che segue comunemente in Settembre o in Ottobre, ed è preceduto da un unore giallastro viscosetto e spumoso, che le cola dalla vulva) va in cerca di una terra incolta, leggiera, arrendevole, screpolata (I), sabbiosa, calcarea, vulcanica, ben esposta e riscaldata dal sole, e impenetrabile dalle acque; qual si richiede per essere agevolmente sommossa e ben ricevere e conscrvare le ova. I fondi di tal natura, di che abbondano le nostre spiagge, per essere ingrati e sterili si trascurano dagli agricoltori, e si conoscono sotto i nomi volgari di grillaje, appezzamenti e mezzagne sodive, terrinelle, pozzolanelle, tufarine ec.

S. 25. Allorchè la femmina si acconcia per isgravarsi, inarca il ventre dall' ultimo pajo di gambe fino all'apice del. la coda : si appoggia sn tutte le tre paja, mette in azione gli organi scavatoj, poichè non si può dubitare, che le quattro appendici da noi cosi denominate (art.3.) e componenti una maniera di pungiglione, non equivalgano in quanto all'uso a que' punteruoli che evidentemente appariscono nelle femmine del Genere locusta di Fabricius, confuse fin qui con quelle del Genere acrydium, nel quale soltanto si comprendono le specie nocive all' agricoltura. Colle descritte appendici sollevando la terra e togliendosela dappresso, si scava una fossa capace di contenere una parte del suo corpo. Ciò fatto, presa da contrazioni lascia ad una ad una cadere le ova dentro il nido che si è costruito, (2) spruzzandole alternativamente del glutine spumoso che dee congiungerle; e cosi si resta immobile per più ore finchè si è sgravata di tante ova, quante bastano a riempire la descritta cavità. Si è asserito come cosa di fatto (3), che più maschi concorrono alla escavazione della fossa insieme colla femmina, e centri-

(1) Locis planis et rimosis;pariunt enim in rimis sua ova (Arist. de part. an. lib. 5. c. 28.) Non nascuntur nisi in planis et rimosis locis. (Plin. lib. It. cap. 29.)

(2) (Arist. op. c. lib. 5. cap. 38. Non summae telluri partus committitur , sed paulo allius.

(3) Doria op. cil. pag. 67. (Senni p. 23.). 
buiscono il glutine: che da una sola femmina si hanno fino a sette o otto cilindri; e clie dopo ogni parto torna a congiungersi col maschio, lo che a dir vero poco o nulla interessa. Noi più volte abbiam veduto le sole femmine prepararsi il nido e scavarsi entro la terra, senzajuto de'maschi, una fossa, ove deporre le ova, la qual cosa ci sembra conforme alle leggi della natura; imperocchè come potrebbe il nuaschio associarsi al lavoro senz' esser dotato degli organi scavatoj come la femmina? Inoltre ne'soli animali monogami e non mai ne' poligami il maschio prende curadella prole in un colla femmina. In quanto al numero de'cilindri ; non siam lontani dal credere, che una sola possa comporne piì d'uno; poichè avendo aperto il ventre a molte locuste gravide, vi trovammo fino a 43 ova, numero assai maggiore di cuello elie si racchinda in qualunque cilindro, ove rade volte se ne contano più di trenta. Il glutine disseccandosi stringe le ova, forma loro una crosta all' intorno, e $s^{\prime}$ impasta colle pareti terrose: il cilindro, o guscio che ne risulta (cui si dà nome anche di ovaja) avendo maggior consistenza del suolo, può esserne separato per intero ed estratto dalla cavità che riempie : è alquanto curvo, ( Fig. 7. 11. I.) grosso tre linee, lungo sette (r) : la sua estremità superiore emisferica trovasi a fior di terra: lo strato che la ricopre lia la. grossezza di una linea all' incirca : il glutine che $l^{\prime}$ ottura è in istato fresco di un bianco lucido argenteo, rarefatto e spugnoso, forse perclıè frangasi agevolmente allo sbocciar della prima larva: essendo poco o nulla solubile nell'acqua, impedisce, clie i cilindri s'increspino pel gelo, o si fendano pel caldo; ma le assidue e copiose pioggie lo decompongono. Le ova trovansi disposte entro $\mathrm{i}$ cilindri in sette o otto piani paralelli più o meno inclinati: ad ogni strato di ova si frappone 1110 strato di glutine : ogni ovo che se ne stacca lascia scolpita la cavità nella quale era internato e rappreso. Le ova sono cilindriche, alquanto curve, larghe mezza linea, lunghe tre; chiare, diafane come la gomma del prugno; dure, ma elastiche, e se comprimansi fra le dita, scoppiano nel frangersi : ogni cilindro ne racchiude da ventiquattro fino a trentasei. Le ova immature contenute ancora negli ovidutti.

(1) Ut quasi favus esse videatur. ( $\Lambda$ rist. ibid.) 


\section{4}

motano entro $\mathrm{m}$ fluido giallastro, la cui quantità decresce in ragione che le ova maturano. A queste, che possono facilmente sgretolarsi sotto le dita, alluder volle Aristotile (1), allorchè disse, essere le ova delle cavallette cotanto molli, ut solo attactu elidantur. Nel momento del parto poi trovansi avviluppate in una bianca tennissima spuma, che disseccata si fa nera e spugnosa; ed è il descritto glutine che le accompagna per servir loro d'intonaco.

S. 26 . Se le nostre cavallette si facciano partorire in piccolo spazio artificialmente sparso di gramigne e di sabbia, cui sovrappongasi una campana di cristallo, alcune depongono le ova sotto l'arena, ed altre sulle gramigne; queste però non damo alcun prodotto, ma dalle prime soltanto vengon fuori le larve. Da tale sperienza si può fondatamente congetturare, che le ova delle cavallette partorite sopra terra non nascono, sia clie trascurino di deporle sotterra, perchè non sono gallate, come opina il Zinanni; sia che 1'istinto loro venga perturbato e deviato dall' angustia del luogo . Ulteriori sperimenti ci faranno conoscere con certezza, se avvenga delle cavallette, come degli altri ovipari, le cui femmine cuantunque celibi partoriscono ova che nulla producono. Gioverà per ultimo l'avvertire, che le locuste armate di pmernolo, le quali e dallo Scufonio, e dall'anonimo Toscano e dal Signor Doria sono state confuse colle cavallette devastatrici, non iscavan fosse e non le riempion di ova; nè mai più di un ovo depongono ne!lo stesso luogo, passando a scgravarsi del secondo poco lungi dal primo, e cosi successivamente; dal che ne segne, che la formazione de' cilindri è propria degli acridj, e non già delle locuste. (2) S. 27 . Il rigore del verno e le stagioni piovose spengono la virtù prolifica organizzatrice delle ova : la siccità ed il calore l'avvivano e la fomentano (3): incostante è l'epo$\mathrm{ca}_{2}$ in cui ne sorgon le larve, perchè ritardata, o accelerata dalla temperatura della stagione, dalla esposizione e dal clima . Quando la terra s'intepidisce e rirverde, quel-

(1) Arist. ibid.

(2) Pariunt in terra, fixo cauliculo, quo mares vacant. (Árist. ibid.) Pariunt in terra, demisso spinae canle, ova condensa autumni tempore. Ea durant hieme sub terra "(Plin. H. N. lib. 11. cap. 29.)

(3) Vernis aquis, incercunt ova: sicco vere major proventus. (Plin.ibid.) 
Te che trovansi piì vicine alla superficie (prima delle altre ehe si ascondono più addentro) s' inturgidiscono per certo tal moto fermentativo intestino. Nel 182 I le larve della nostra Specie non nacquero che a niezzo Aprile pel prolungamento del verno: a quell' epoca le terre stesse ove sorsero, comnncue incolte, eran vestite di gramigne e verzura; perciò non ebber luogro a danneggiare i pomarj e il fiumento. Se la temperatura naturale o artificiale il comporta, le cavallette nascono in ogni tempo, e possono aversene più generazioni in un anno: Zinanni ne trovò intirizzite ncl colno del verno: ravvivate al calor di una stufa crebbero, esaurirono la lor metamorfosi e si riprodussero : se l'inverno è temperato ed asciutto, avviene naturalmente che nascono in primavera, partoriscono in autunno, e muojono poco dopo; ma essendovi anomalie nelle stagioni ed insolite vicende atmosferiche, accade ciò che Plinio c Aristotile (r) disser di loro; che si sgravano al sorgere delle plejadi, cioè al fin di primavera, periscono al nascere della canicola, e rinascono al tramontar di arturo.

S. 28. La prima larva che esce dall' ovo ne frange il guscio col capo, e vien fuori colle prime due paja di gambe, forando l'estremità superiore del cilindro, che a tal uopo è debolmente otturato $(\$ .25$. $)$ : le altre larve la sieguono; e poichè molte ne sbucano ad un tempo, veggonsi a stuoli coune bulicar di sotterra, traendosi dietro una parte del guscio, di che si liberano dimenandosi. La larva (Fig.3.n.1.) ha già le antemne ed i palpi formati : è grossa una linea e mezzo, e lunga quattro: la sua cute è oscura con macchie più cariche : degli astucci e delle ali non si scorge vestigio : le locustine poco slontanansi sulle prime, nè si scompagnano, rimnendosi in diversi piccoli gruppi poco distanti fra loro nel fondo stesso in istretta società : gुà per natura vivaci, tanto più il divengono, quanto pin nutronsi : dopo quindici, o venti giorni, demulate le vicimanze della terra natia, si diramano in colonie e si sbandano, più lunga stazione facendo ne'campi di più ricca pastura. Un mese all' incirca dopo la.

(1) Arist. ibid. "Pariunt exilu veris. ," (Plin. ibid.), Vergiliarum cxortu parere, deinde ad canis ortum obire, et alias renasci. Quidamaiaturi occasu renasci. 
nascita la larva si spoglia per la prima volta dell'epidermide: questo inelastico tegumento forzato a distendersi pel crescere del corpo, che vi si racchiude, si squarcia e si fende longitudinalmente sul dorso: il digimo e l'inerzia precedono questo periodo; l' insetto va in traccia delle varie specie di cardo, o della pastinaca (Scolymus hispanicus), o del finocchio (Anethum foeniculum ) o di arbusti e di frutici laceranti e pungenti; contro i (quali corpi ha 1 ' istinto di stropicciarsi. Sovente le spoglie delle cavallette trovansi appiccate sui cardi : son trasparenti, sottili, senza colore, e vi si scorgono delineate tutte le parti del corpo che rivestivano. La giovane cuticola, che l'era sottoposta, è piu nitida, più flelicata e più vivamente colorita. La larva dopo la muta restasi torpida per qualche tempo, finchè forse la nuova epidermide s'avezza a risentir le impressioni della luce e dell'aria. Venti giorui dopo all'incirca cambia di pelle per la seconda volta, dopo di che mostrasi in forma di ninfa (Fig.4.11.1.) con un principio di ali e di astucci, la cui lumghezza non è maggior di tre linee. In questo secondo stato le carene laterali sono lineate di un bianco rossastro: fia i segmenti del torace vi sono due fasce nere orizzontali, orlate di bianco, della larghezza di una linea. Dopo un egual periodo presso a poco di venti giorni, compie la sua metamorfosi ed apparisce in istato ditotal perfezione (Fig. I.n.1.) colle ali atte al volo, e coi loro muscoli in pieno sviluppo. In questo stato non più transitorio, ma permanente, l'insetto per lo spazio di un mese in circa non attende che a nutrirsi : poche sono le piante ch' egli rifuta: tutte le divora promiscuamente, non esclusa la cicoria (Cichoreum inthybus) e la vite (Vitis vinifera): i vegetabili, ch'egli risparmia, per quanto è a nostra cognizione, sono, la noce (Juglans regia), il salcio (Salix viminalis), l'eringio (Eryngium campestre), il pomodoro (Solanum lycopersicon), il tabacco (Nicotiana tabacum), i riscoli (Salsola soda), la felce (Pteris aquilina ) ec. Si accinge a lunghi ed arditi voli agevolati talvolta dal soffio del vento da cui è tratto; non però dai torrenti e dai fiumi, al corso dei quali egli non si abbandona, come hanno scritto taluni : noi abbiamo osservato, che le cavallette non si lanciano in acqua spontaneamente; e se il vento le spinge, poco resistono al nuoto, e periscono ben presto per l'umidità e pel freddo della temperatura. Finalmente 
rnasi la propria esistenza obbliando volgono ogni cura a riprodurre la loro Specie: il maschio dopo aver fecondata la femmina, e questa dopo aver deposte le ova, periscono, o vivon digimui fino a vénti e trenta e più giorni.

S. 29. Ora è per ultimo da vedersi per qual casgione avvenga la morte di entrambi dopo aver soddisfatto alle funzioni sessuali . Aristotile (I) lasciò scritto, che immediatamente dopo il parto nasce intorno al collo delle cavallette un verme che le uccide: "pariunt exitu veris, et statim moriuntur, vermiculo circa collum innascente, qui eas strangulat. , Cotesti vermi parassiti, bianchi, sottilissimi, elastici e vivaci, che appartengono al Genere Filaria di Ruclolphi (2) trovansi talvolta in realtà negli ovidutti delle femmine ( ne' maschi non ve ne la esempio); in una delle quali il Zinanni ne vide fino a cinque. Dalle più accurate, e ripetute osservazioni per altro rilevasi,

I. Che i vermi s'anuidano nell' addomine delle cavallette rare volte, e nelle femmine soltanto. to dopo.

2. Che ciò avviene loro, tanto prima del parto, quan-

3. Che trovansi soltanto in quelle, che han divorato i cadaveri delle altre cavallette.

4. Che i vermi esistono promiscuamente e ne' cadaveri, e in quelle che si aprono viventi. morte.

5. Che possono essere evacuati per l'ano, senza dar

6. Che in realtà sono talvolta causa di morte, perchè corrodono gli ovidutti e traforano il corsaletto. Dalle quali cose rilevasi, la verminazione delle cavallette essere un morbo incidente e non abituale, nè sempre cagione di morte, derivante forse dal vitto animale, ch' è loro eterogeneo; e non esser vero che muojono tutte dopo il parto; poichè se avviene sovente il trovarne morte non poche nel

(1) Arist. de nat. an. lib. 5. cap. 28. (Plin. ibid.) Mori matres cum pepererint certum est, vermicnlo statim circa fances innascente, qui eas strangulat. Eoden tempore mares obeunt.

(2) Entozoorum synopsis, Bedolini $1819 .$, pag. 11. Filaria locustae Fnt. 1. p. 77. 11. 36. F. locustae. Hab. in locusta vividissima . Frisch. in L. verrucivora. Roesel. in L. Henitogia Cat. Ent. Vien. Nos in acrydio ikalico (V. Zinanni op. cit. p. 8. 9. tab. 1. 22. 3 . 
Inogo stesso ove han deposte le ova; avviene altresi , che molte ne sopravvivano dopo il parto fino a trenta e pir gioni. Generalmente però soggiacciono al destino di mua gran parte degl'insetti, ne' quali la natura non prezza più l'individuo, dopo aver provveduto alla conservazione della specie. La morte di entrambi non dipende aduncue nè da vermi, nè da altre cagioni immasinarie, ma bensi dal non prendere cibo di sorta alcuna dopo il parto; infatti se al di là di quest'epoca aprasi loro il canal digestivo, trovasi vnoto, arido e smunto; la qual cosa essendo costantissima, non occorre imbarazzarsi in cer-. care altre cagioni di morte oltre l'inedia.

\section{A R T I G O L O VI.}

\section{Se la Specie di cui si tratta sia straniera, o nativa d'Italia.}

S. 30. LA Specie, o Varietà che abbiamo descritta potrebbe essere per avventura confusa coll' Acryclium migratorium, o col Germanicum, avendo con questi alcuni caratteri in comume. Il migratorium ( fig. 2.11. . .) si riconosce per la maggior lunghezza del corpo ch'è di linee 19 all'incirca nella femmina: 14 nel maschio : ha le antenne più lunghe del torace; e questo con una sola carena, ed un solo segmento: due linec oscure si estendono dagl' occhj paralellamente fino ai lati della base del torace; le ali (fig.2.n.2.) sono trasparenti di un giallo che tende al verde sbiadato: le tibie posteriori cernlee, armate di denti bianchi coll' apice nero : l'interno de' femori macchiato di nero. Gli astncci variano per la forma delle macchie brune angolose, o in figura d'occhi o di caratteri. Il colore del corpo è di un verde brumo con macchic nere, o di color cenerino sbiadato o rossiccio : le mandibole di un torchino che volge al nero. La frase specifica, che crediam convenirgli, è la seguente." $A$. thorace subcarinato, segmento unico, mandibulis caeruleis, alis hyalinis, dilute ad basin virescentibus ., - Questa Specie non è abbondante o comune presso di noi, nè vive in società: se ne trovano pochi individui isolati nella valle dell'Ariccia, e riuniti di rado in piccoli gruppi..

S. 3I. Si è sempre creduto, che la Specie fatale e desolatrice delle nostre campagne sia esclusivamente l' $A$. mi- 
gratorium : che i bollori e la siccità de' più smaniosi estivi giorni ne spingan d'Affica fino ai lidi d'Italia eserciti innumerabili o sulle proprie ali, o su quelle de'venti d' ostro e di lebeccio : clie ad onta del vasto mare che vi si frappone ginngan salvi ed illesi, anzi agili e pronti a nuocere e a riprodursi. Plinio ( $\mathrm{I}$ ) che narrando fenomeni naturalmente inesplicabili, spesso fa dubitar di sua fede, rideasi del preteso errore degli antichi, i culali, a parer nostro più ragionevoli di lui, avean per certo, che le ali delle locuste bagnate dall'umidità e intirizzite dal freddo, divenissero inabili al volo in tempo di notte: ignari, dic' egli, etiam longinqua maria ab iis transiri continuata plurium dierum profectione. Giuraron tutti non senza stupore sulla pliniana autorità e per tutti l'infaticabile Aldrovando concluse, divini aliquid in alto eo volatu est. L'Anonimo fiorentino credulo anch'esso oltre modo non sa contenersi, dicendo esser cosa più simile al prodigio che naturale il poter travalicare mari sì vasti simili bestiole; ed il dotto Zinannni riflette, che il viaggio d'Africa in Italia è smisnrato, e quindi inesegnibile dalle locuste. L’imparzial Bowles nel descrivere i danni prodotti dalle locuste nel i 754 , dimostra trionfalmente colla tradizione e colla storia, che la locusta dalle ali color di rosa, cui debbonsi le freçuenti invasioni della Spagna, è assolıtamente indigena di quel regno, e gl' incolti terreni dell' Estremadura ne sono il perenne vivajo; che se venisse d'oltremare, questo passaggio sarebbe noto, come lo è quello delle quaglie e di altri uccelli trasmigranti.

S. 32. Il Signor Doria (2) a difesa del chimerico oltremarino passaggio, allega un fatto narrato dall' accuratissimo Adanson, il quale viaggiando al Senegal vide presso il fume

(1) (Plin. lib. 11. cap. 29.) Gregatim sublatae vento in maria, aut stagna decidunt. Forle hoc casuque evenit, non ut prisci exislimavere, madefactis nocturno humore alis. Iidem quippe noctibus non volare eas prapter frigora tradiderunt, ignari etiam longinqua maria ab this transiri, continuata plurium dierum profectione... Sufficiunt quippe vires, et tamquam parum sit maric transire. immensos permeat tractus, diraque messibus contegunt uube ... Italiam ex Africa magna colorte infestant, sacpe populo ad sybillina coacto renedia confugere, inopiue metll etc.

(2) Introduz. p. 23 . 
40

Gambia nna folta muhe di locuste all'altezza di 180 piedi da terra, che oscurava l'orizzonte: ad un tratto, come piovendo a scroscio, si posò a terra e distrusse quanto v'era di verde ; risali quindi, ed impiegò tutta la giornata ad oltrepassare il paese adjacente. Per verità il trasferirsi d'ma in altra regione limitrofa in un giorno non equivale al passar d'Atirica in Italia, che appartiene ad un altra parte del mondo, e non è certamente vicina all'Affrica: lo spazio percorso, per quanto grande roglia supporsene la distanza daile rive del Gambia, non dovette essere di molta estensione, giacchè trattavasi di paese adjacente; eppure non vi volle meno d'un giorno: quanti ne avrebbero impiegati per volare fino alla spiaggia romana?

\$. 33. Ma esaminiano la possibilità di tal portentoso tragitto. Nulla di pin sfavorevole alla vita delle cavallette che la forza del vento e l'unidità : soglion desse evitar per istinto le correnti d'aria troppo rapide, e i gagliardi colpi di vento; che se ne sian tratte, e ne divengan ludibrio, o periscono, 0 restansi a lungo tramortite ed inerti (2). Niente men funesta è per esse l'umiditì : basta quella della notte per intorpidirle, e paralizzare $\mathrm{i}$ muscoli delle loro ali : anche a mezzo Agosto (e ben piu volte il vedemmo) si levano a volo nom prima delle nove ore del mattino, e posansi e prendon quartiere circa le sei della sera. Come adunque nella nostra ipotesi e la notte, e il vapore acqueo, e la furia del vento, che sono cagioni di letargo, di asfisia e di morte, divengono per le cavallette avventurose sorgenti di attività, di vivacità e di risorsa, che ne accelerano $\mathrm{i}$ moti, anzichè ritardarli; che, aumentandone il vigor fino al colmo, destano in esse l'appetito venereo? Il viaggio d'Affrica non è da compiersi nel breve giro di poche ore diurne; dovrà impiegarvisi ancor qualche notte; ed in questa, oltre $\mathrm{i}$ vapori che s'addensano in brine e in rugiade, che precedono la comparsa del sole, è da considerarsi la privazione della luce, l'abbassamento di temperatura e l'evaporazione delle acque marine; inoltre $i$ venti meridionali son pregni d'umidità; e ben cel dicono i nostri boschi, che ne frangono l'impeto, e ne assorbono il

(2) Ante ortum solis a loco cui insederant non movebantur, orto sote demum per cohortes suas proficiscebantur. (Aldrov. de ins. p. 422. 
veleno. Perchè l'azion sinultanea di queste cagioni mancherà di agirc sulla delicata costituzione de'nostri insetti, sensibili per organismo alle piic lievi impressioni atmosferiche?

S. 34. Ma concedasi loro il poter di resistere : sotto qual forma crederem noi che si acciugano all'arduo viaggio? Non certamente di lalva, o di minfa, perchè in questi due stati son prive di ali, o nou ne hamno che gl' imutili rudimenti; dunque in figura d'insetti perfetti, compinta la lor metamorfosi ; cioé in quell' epoca della vita, che snol essere la piu fatale; dunque nell'ammo in cui giungono dovrebbe aversene il più gran nocumento : eppure i damni anmentansi regolarmente di anno in anno; nel primo ne sboccian dalle ora hen poche larve, delle quali si vede gradatamente il passaggio di stato in istato fino al completo sviluppo : finalmente chi fu mai testimonio del loro arrivo? Chi le vide approdare, congiungersi, deporre le ova? Chi ne prevenne, o ne predisse le couseguenze? Quanto imponente fu il loro numero nel primo anno della loro comparsa, e tuali campague ne fur desolate? La vista di folte mubi animate, che si scaricano su i campi, non d̀ già un fenomeno tanto comune, che non colpisca gli acchi de' men veggenti e non arrechi sorpresa; perchè dıuque si vuol ricorrere al prodigio, quando evidentemente apparisce, che esiste presso di noi una Specie di cavalletta nociva al pari della migratoria, e per tale riconosciuta anche in altre parti d'Europa, che, ricoryendo stagioni aride e calde, si moltiplica enormemente e distrugge ogni maniera di vegetazione? Era ancor bambina la zoologia (I) ruando scrivevasi la storia de' damni arrecati dalle locuste . nè si pensava clie cadesse dubbio sulla Specie, stimando che fosscro tutte eguali, o che poco interessasse il determinarne i caratteri distintivi; quindi è che nulla si può raccogliere dalle notizie, dalle descrizioni e dalle figure, nelle quali si trova sempre confuso il Genere acrydium col G. locusta (2). Il

(1) La zoologia era givi adulta nel 1816 , eppure si avea coraggio dí scrivere in Roma a quell epoca, che le differenze fra le cavallette sono accielentali, e non possono essere specifiche. (Doria l. c. intr. p.xxiv.) Ne sutor hitra crepidas.

(2) I earatleli fin qui asseguati all' acrydium italicum non erano suffi. cienti pereliè fosse ad cvidenza riconosciuto, e non confuso con altre Spccie: nou $v$ 'ha alcnn entomologo che indichi per carattere esclusiramente 
42

credulo volgo colto dallo spavento non sapendo concepire come insolgano stuoli cotanto folti d'insetti, che dianzi non apparivano, $s$ immaginò che venissero d'oltue mare; ut ex regione remotiore adportatas credant, quas sua terra produxit locustas.

S. 35. Riflettiamo per un istante sulla storia dell'ultima jiruzione descritta con sufficiente esattezza dal Signor Pomponio Senni (I) : „, Al nascere della primavera (dic' egli alla pag. Io.) dell'anno 1807 apparvero nelle campagne delle terre di Marino ed Albano alaune piccole turme di locuste; ma la poca quantità non ne fece valutar l'esistenza,, S'amnidavan dumque le ora in que'territorj; e vi furono certamente deposte fin dall'autumuo del I806; dunque le femmine della pretesa locusta migratoria vemner $d^{\prime} \Lambda f_{r}$ ica in Italia fin dall'anno antecedente; ed in quale stagione? Naturalmente ne'più caldi giorni d'estate; nè già in autumno, se pur non vogliamo illuderci fino al punto di crederle tolleranti delle piogge, del freddo e della stagione che volgre all' inverno: fu dunque nel colmo $d^{\prime}$ estate che approdarono cotesti insetti invisibili; nè vi fu cli li vide, o n'ebbe notizia, o ne sospettò l'arrivo. Giunti a terra si stettero immobili, nascosti, digiuni (raro esempio d'astinenza in insetti cotanto voraci) e sempre invisibili, nè fecero aleun danno: $v^{\prime}$ eran pur delle ricche pasture intermedie fra il mase e la città di Albano, e furon salve cd intatte : la celebrazione de'loro sponsali fu del pari sconosciuta, misteriosa ed arcana; e $v^{2}$ eran pur terre sabbiose in gran copia presso la spiaggia acconcie a ricevere i loro parti; e ben si conobbe in questa medesima invasione quanto sian propizie le arene marittime a conservare la loro specie, che inseguita per sette anni e ormai spenta si rifugiò nelle terre sabbiose di Tor-

proprio di questa spccie il corsaletto con tre carene, ed altrettanti segmenti che le traversano: Linneo (Villers tom. 1. pag. 443.) lo descrive thorace subcarinato, absque segmentis : alae fascia arcuata nigra, inter fasciam, et corpus sanguineae: quest'ultimo carattere è proprio dell' acrydium germanicum. (Vedi Latreille tom. 12. p. 156.) (Pelagna Entomol. tom. I. pag. 3 I g.) (Rossi Fama Etrusca tom. 1. p. 270.) (Fabricius syst. ent. 29r.)

(1) Raccolta di osservazioni sulla propagazione delle locuste ec. Roma $181 \%$. 
paterna (1) donde lo snidarla fu impresa assai malagevole . $\mathrm{E}$ se trasandarono le prime terre più prossime al mare, perchè almeno non preferirono ai colli albani la valle d'Ariccia, che per la sua freschezza, amenità e fecondità presenta anclı' ogggi un asilo pressochè esclusivo ad alcuni individui della Specie migratoria? Perchè finalmente da immense legioni non si ebbe che un piccol numero di locuste, sicchè la poca quantità non ne fece valutar l'esistenza? Ci si risponde, che non un esercito, ma un piccol drappello di femmine gravide s'inviò di colà, forse colla benefica mira d'introdurne la Specie presso di noi; e che in tal condizione, siccome è certo, non arrecan più nocumento co' denti ma colle ova. Non è men certo però, che le colonie, nelle quali esse diramansi, non si smembrano dal corpo se non per mancanza di pascolo e di alimento, e non mai per bisogno di terra ove sgravarsi, di che abbonda la Libia arenosa: che le locuste gravide son pigre, inerti e pesanti; per poco sostengonsi a volo, e non abbandonano il suolo natio: la cural cosa ripugnarebbe alle leggi della natura, e all' istinto loro, e ai loro costumi.

S. 36. Resta ora a vedersi se la nostra cavalletta si possa confondere coll' $A$. germanicum. Questa Specie esiste ne" contorni di Roma, ma non è frequente, e non vive in società : di color bruno, con varie macchie più chiare; colle elitre macchiate di nero: di una metà più breve dell' italicum: ha il torace con una sola carena ed un solo segmento: le ali rosse color di sangue con una fascia nera, che partendo dall' angolo interno del margine posteriore scorre lungo i due terzi di detto margine; salisce quindi rịolgendosi intorno al margine anteriore esterno, e si estende fin presso la base dell'ala: l'angolo estcrno con una parte dell'estremità dell'ala sono: trasparenti. Linneo ed altri molti dopo di lui lo confondono coll' italicum, omettendo nella descrizione delle ali la fascia negra (2): gli esemplari che abbiamo raccolti coinciclono esattamente colla nostra descrizione.

(1) Nell'anno 1815 le ultime loensle si rifugiarono nel quarto di Parcigliano, suolo arenoso, circondato da folta ed estesa macchia, ove deposer le ova ( V. Doria op. cil. pag. 7!. )

(2) Testaceus, alis sanguineis apice hyalinis, femoribus posticis nisro-punctatis. Linn. (Villers 1. 452.) (Petagna entom. 1. 318.) (Roe- 
S. 37 . Ci si opporrà, perchè questa Specie indigena d'Italia, e forse anche dell' Europa temperata non si riproduea annualmente in si gran numero, e non arrechi egiral danno in ogni stagione. La fecondità degli esseri organici dipende dallo stato igrometrico, termometrico e forse anche clettrico dell'atmosfera: le piogge dirotte e fiequenti, $i$ venti settentrionali impediseono lo sehindersi delle ova : la siccità ed il tepore ne promuovono lo sviluppo. Nè eiò avviene alle sole ova delle cavallette :non in tutti gli ammi nasce egual copia di bruchi, che ci divoran le viti, le olive, le gramigne, i cereali e le frutta. Nel ${ }_{1}{ }^{3} 7$ si vide a Ravenna (1) una quantità sterminata di una specie di ruche, che divoravano tutte le fave; e reeava stupore il vederle entrare a turme in città : nell'anno seguente se ne perdette un gran numero, e quindi gradatamente e senza opera minanx seomparvero. Nel r8r5 (2) la larva della Plualena nocture oleracea di Linneo ne'territorj di Palestrina e di Cave s'era talmente moltiplicata, distruggendo gli ortaggi, i seminati, le vigne, e particolarmente i grani d'India, che la S. Consulta inviò colà i suoi periti Sanitarj, chiedendo loro i mezzi di estirpazione. Il voracissimo bruco della Phalena tinea evonimella di L. spoglia sovente i riechi pomarj di Rocca di Papa e di Nemi, minaccia que' di Marino, Grotta-Ferrata e Frascati (3): ambedue cotesti bruchi si aumentan purtioppo e si estendono ad onta di qualunque più energica provvidenza; ma ad ogni più lieve (ed a noi spesso impercettibile) atmosferiea vicenda, se n'esaurisce la feeondità e sembra che se ne perda la specie (4). I morbi epidemici e contagiosi si comportano allo stesso modo : insorgono senza cause evidenti sotto certe condizioni atmosferiche : $s^{3}$ indeboliscono, si spengono, si ravvivano: gli stessi contagj o indigeni, o stra-

sel. t. 2 I. fig. 7.) (Olivier. criquèt á ailes rouges.) (Latreille tom. 12. pag. I5. ) Le altre specie di Acrydium più commi nelle ,nostre campagne sono $\mathrm{l}$ 'A. stridulum, cacrulans, caerulescens, lineola, flavum etc. ( V. i loro caralteri in Fabr. $28 \mathrm{~g}$. (Lin. Villers r.p. 4 1.., Petagna (inst. cntom. I. p. 3ı6.) Rossi ( F. Etr. 1. p. 269.) (Latreille hist. des ins. t. 12.p.:50.)

(1) Zinami dissert. sulle cavall. p. 37 .

(2) Metaxa mem. zoolog. pag. 28 .

(3) Metaxà ibid. p. 24 .

(4) Doria ibid, intr. p. 29. 
nieri, o naturalizzati talvolta ascondonsi inoperosi : illanguidita, e spossata ne sembra la forza di riprodnzione : talvolta ad un tratto d' uno in un' altro commicandosi, mietono vittime senza numero: la stessa peste d'oriente cessa spontanea, e ripullula ad epoche presso che determinate nel nativo suo clima: 1' impero déle meteore sul globo è il quid civinum d'Ippocrate.

S. 38. Alla diuturnità e al riggor dell'inferno deesi infatti, se ne' tre ultimi decorsi anni i prodotti della campagna non furono preda delle cavallette, le cui larve essendo uscite dalle ova a primavera avanzata trovaron pascolo per ogni dove, e prima che la lor metamorfosi fosse compita, le spighe divennero adulte e mature, e fur cosi risparmiate ed illese. Che se ne'venturi anni l'inverno fosse men pioroso e più dolce, la loro numerosa posterità sarebbe certamente fatale; ond'è che lungi dal trarre argomento di un più lusingliero avvenire dalla sperienza del passato, dobbiamo occuparci con tutte le forze della estirpazione delle ova e della distruzione delle lárve; che passando allo stato perfetto, colle ali dispiegate e gia pronte al volo, resistono ad ogni umana persecuzione.

\section{A R T I G O L O VII.}

\section{Modi di estirpazione.}

S. 39. U A lunga durata di questo flagello e la diflicoltà di prevenirlo e svellerlo dalle radici derivano a creder nostro dalla erronea opinione comunemente invalsa, che le locuste desolatrici siano straniere : che non esistan fra noi se non quando vi giungon d'Affrica o di Tartaria colle ali ben dispiegate e perfette : che tal repentina invasione non ammetta rimedio se non tardo ed incerto : che il nostro clima sia lor favorevole a riprodurle colla stessa fecondità, non però fino a naturalizzarle. Imperocchè non essendosi mai veduta presso di noi la locusta migratoria rimita almeno in piccole società, o frequente in più luoghi (fenomeno non comune in natura, che gli animali non abbiano d'accostumarsi a quel cielo, sotto il quale prolificano felicemente) converrebbe dire, che al cessar dei danni se ne estingue la specie. Per tal complesso di errori il germe della locusta no- 
46

civa si giudicò irreperibile nelle campagne romane, e il poter nostro limitato a combatterla adulta. La qual cosa essendo di ardua riuscita e di spesa eccessiva, fu praticata con poeo o nim frutto; e in ciascuna irruzione ad onta de' più vantati metodi distruttivi le locuste si moltiplicarono progressivamente.

S. 40. Per verità il supporle oltremarine giustifica pel primo anno l'inutil sistema di perseguitarle pinttosto in figura d'insetto perfetto, ehe in quella di larva; ma ne' successivi anni essendo eerto, ehe partoriscono nelle nostre terre, perehè non combatterle in istato di ovo o di larya? Nella invasione del $1807 \mathrm{~m}$ intero biennio ( 1807,1808 ) si passó nell' inerzia : nel 1809 si volle attaceare l' insetto alato per mezzo delle tende; e qual ne fu l'esito ? Centuplicata ( dice il Signor Senni alla p. 12.) fiu l’infezione del 810. Non sarebbe certamente avvenuto così, se si fossero diretti contro le ova o le larve.

S. 41. Stabilito ora, che la cavalletta nociva nasce e

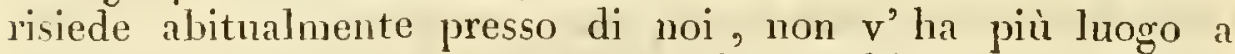
concludere, che sia inevitabile il danno eh' ${ }^{\circ}$ essa ne arreca, perchè giunge d'Affrica in istato perfetto : è in libertà nostra lo scegliere quel periodo della vita, in cui può farsene la più certa e pii ricca preda colla maggior possibile economia e facilita. Estinguere la Specie sarebbe opera piu che umana :

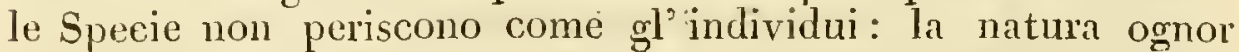
feconda in risorse le scrba illese e perenui a dispetto delle meteore e degli uonini che osan tentame la distruzione. Che la locusta italica esista in pieciol numero non può impedirsi, e non è di nocumento; non può impedirsi, che le stagioni propizie, o altre ignote cause le aumentino; che il numero delle femmine prevalga talvolta su quello de'maschi (I), ma può ben diminuirsene le quantità, riducendole a poche, come sono abitualmente nelle nostre campagne senza damno sensibile dell' agricoltura.

(1) Alla insolita moltiplicazione delle cavallette influisce anclıe il scsso degl'indiviclui che nascono: osserva Bowles (Storia di Spagna pag: 2.), che l'invasione delle cavallette avvenuta in Ispagna nel 1754 dovette ripetersi in grau parte dal copioso numero delle femmine, che prevalse di gras lunga a quello de maschi: un maschio può fecondar molte femmine. 
S. 42. Lo stato di larva è il più opportuno per consequire il bramato intento: le larve shocciate appena dall'ovo si stanno concentrate e ristrette in piccolo spazio di terra: son deboli e prive di ali e di forze : il freddo, i vapori, le rugiade e le brine le rendon torpide ed immobili. Cuppransi di paglia ben ascintta sul far del gुomo, o sul far della sera le sterili terre infette dalle nascenti locuste, dal primo fino al vicesimo giorno di loro età : se ne circondi la periferia : vi si appicchi il fuoco da più lati : le locuste rimarran certamente vittime dell'incendio. Na le ova non tutte schindonsi ad un tempo, o per differenza di epoche, o di esposizione pin o meno meridionale; perciò il fondo ove s'annidano vuol' essere visitato per piu giorni consecutivi, ad oggetto di ripetere la comhustione se appajono nuove locuste. Con tal metodo fedelmente eseguito in tutti i fondi, donde sorgono le larve, la più gran parte di loro resterà incenerita. Dopo venti giorni circa, denudato il suolo natio, si scioglie la lor società, e si dirama in varie colonie per cercare alimento: l'accingersi alla lor distruzione in questo stato è impresa malagevole, dispendiosa e di pochissimo fiutto : le tende e le fosse sono i mezzi, de' quali si è fatto uso per dar loro la caccia. Fin dal r $7^{1} 6$ si formarono ampie tende quadrate con un sacco annesso a ciascuna da aprirsi per di sotto. Dispiegavansi le tende ( poichè i nostri insetti dirigonsi a seconda del vento, e si accampano in luoghi scaldati dal sole, di cui seguono l'apparente cammino ) fra il sole e le cavallette, se l'aria era quieta; se agitata, si esponean contro vento : le cavallette saltellando vi si cacciavan dentro sospinte a bell' agio da uomini muniti di frasche; e quindi con sollevare le tende per gli angoli, ristringeano gl' insetti verso la bocca del sacco, ove cadeano, ed erano poi pestate, e quindi gettate fuori ed arse e sepolte : questa laboriosa operazione ch' esigea l'impiego di molte braccia era affitto inutile per l'insetto alato, e durissima pel desolato agricoltore, perchè alla perdita de’ prodotti agginngeasi il dispendio della contribuzione. Più semplice, ma men proficuo è il metodo d'inseguirle colle frasche, e farle cadere entro larghe e profonde fosse, le quali riempite si colman di terra e si pestano. Sembra che gli antichi facesser conto di questa inutil maniera di estippazione, poichè Livio ci narra, che nell' anno di Roma 569 i romani inviarono in Puglia niente men 


\section{0}

ehe un esereito sotto gli ordini del Pretore Gneo Sicinio per combattere le loeuste; e que' prodi avvezzi a mietere allori cruenti e funchri palme, si credettero umiliati, quasi che sia piu lodevol cosa togliere agli nomini la vita eol ferro, che loro serbarla coll'alimento. Plinio ( 1 ) ei assicura anch'esso, ehe i Sirj e i Girencsi eran per legge obbligati a sterminar le locuste tre volte l' anno: , primo ova obterendo, deinde foetum, postea adultas , i contravventori si punivano militarmente come rei di diserzione : quei di Lemo dovean eolmarne certa misura, e presentarla coattivamente al magistrato; ed avean le cornacchic in alta venerazione, perchè volavan contro alle locuste e le divoravano. La Specie d'Africa e d'Asia è in realtà la migratoria, o altra del pari gigantesca e fatale, che di momento in momento invade e spoglia immensi tratti di terra : altre forze in quelle, altra vita, altra attività: la sorpresa non lascia adito a matura deliberazione: le ova s'ascondon disperse in quelli arenosi infnocati deserti, ed è impossibile il rintracciarle : non v' ha piu distinzion di periodi, o norma costante a seguire:in ogni stagione e nascono e si fecondano promisenamente; e forse in qué climi è necessità l'inseguirle alate e perfette. Ma fosser pure identiche nella specie, regolari ne'periodi; e non dissimile il chima, e gli nomini, e le stagioni e le terre: che perciò? Eran forse infallibili i nostri antichi, clue abbiansi ad imitar ciecamente senza consuitar la ragione ed il fatto? L’incendio può aver lnogo contro le semplici larve sociali, prina che si diffondano : è un perder tempo e depauperare uno Stato, l'ostinarsi nel correr dietro all' insetto, allorchè insieme col corpo gia crebbe in lui il provvido istinto alla difesa e alla fuga : i dami dell' individuo sono un nulla al paragone di quelli ehe si avran dalle ova : contro queste, in che si racclinde la desolatrice posterità che ci sovrasta, tutte essenzialmente concentrar debbonsi le eure. Non si perda adunque di vista qual sia la direzion dell" insetto, e quali le deserte grillaje, che da hii si prescelgono a servir di nido e di cnlla alla generazione ventura. E ben ci si annunziano cotestc terre non colte $(\$ .24$.) al laugnore della vegetazione, e all ${ }^{2}$ essere serepolate e sjarse di forami scavati dai colpi di

(1) Lib. Ir. cap. 29 . 
rostro degli uccelli insettivori, per divorame le sottoposte ova. La presenza de' cannelli o cilindri che le contengono sara argomento invincibile, che appartengono alla specie $110-$ civa; giacchè la locusta dal punteruolo e le altre insocievoli ed innocenti noll fabbricano cilindri.

S. 43. E di somma importanza il determinare qual sia Io stato de' gusci, del glutine che dà loro la consistenza, e delle ova che vi si racchiudono; le quali, o sono distrntte per opera della natura, o devono esserlo dall' industria degli agricoltori : i geli fendon la terra e la espongono al contatto dell'aria: le piogge rovinose ed assidue le rammolliscono macerandole., scompongono il glutine e lo rendon solubile : talvolta le famiglie degl'icneumoni vi si stabiliscono e dan loro il guasto rodendole : coteste larve, cui si dà nome di vermi, furon sovente nella Puglia la salvezza de'canpi. Quando nemici cosi imponenti pugnan per noi, non è più incerto il trionfo : possiam dispensarci dal prender partito: le ova saramno certamente perdute senza la nostra cooperazione. Ma se le stagioni tepide e non piovose van loro a seconda; se gli uccelli e gl'insetti non fan guerra alle ova; se queste trovansi in istato d'integrità, d'uopo è risolversi ed eseguir prontamente ciò che più conviene alla circostanza; cioè, se il solcar coll'aratro le terre infette, o dissodarle e rivolgerle, o introdurvi $\mathrm{i}$ polli o i majali : questi che ne son ghiotti scuoprono i gusci, li sommovon col grifo, e gl'iugojano: tal metodo riusci opportunissimo in Roma nel 1655 . Non ingrato e non insalnbre alimento sono le ova delle locuste anche pe'galli d'India, che voracemente se ne infarciscono senza averne danno, come avviene talvolta agl' ingordi majali.

S. 44. Il tutto ora fin qui narrato ed esposto in breve epilogo raccogliendo, apparisce, che le irruzioni de' nostri campi si devono ad una varietà dell' acrydium italicum, non ancora bastantemente caratterizzata e clescritta, e non già all' A. migratorium, come da Plinio in poi si è sempre fermamente creduto. Il germe di queste locnste esiste sempre ne' fondi non coltivati delle regioni più temperate d' Italia, delle quali è indigena: il piccol numero abituale ne reude? insensibile il nocumento; ma in certe stagioni a lei propizie moltiplicandosi fuor dell'usato denuda le terre di tutto il verde. Se al menomo aumento nel numero, che annualmente si 


\section{0}

riproduce, non è istantaneo il rimedio, i prodotti di quella stagione sono perduti. L'mico provvedimento efficace, economico e agevolmenre eseguibile contro le locuste di fresco nate e ancor deboli ed inermi, è il fuoco: con poca paglia $\mathrm{s}^{3}$ inceneriscono eserciti interi, Venti giorni dopo la nascita le larve diffondonsi, si mettono in marcia, si distribuiscono le terre, e più non temono il fuoco : qualmque guerra che loro si faccia da quest'epoca in poi è affatto inutile: non v'è più da contare che sulla distruzione delle ova: le quali, se per l'inclemenza delle stagioni, o pel nutrimento delle altre specie animali non periscono, devono essere radicalmente estirpate, o dissodando le terre ove s'annidano, o introducendovi i polli, o i majali. 


\section{N D I C E}

\section{DEGLIA R T I G O LI.}

\section{Introduzione.}

Ant. I. Caratteri zoologici della famiglia cui spettnno le cavallette nocive.

Ant. II. Storia de' danni.

Art. III. Determinazione della Specie e descrizione zoologica.

Art. IV. Digestione, respirazione e sistema nervoso.

Art. V. Generazione, nascita, metamorfosi e morte

Art. VI. Se la Specie di cui si tratta sia straniera, o nativa d' Italia.

Art. VII. Modi di estirpazione. 
52

\section{A P P R O VAZIO N E}

Avendo letto attentamente la presente dissertazione non vi ho trovato cosa alcuna contraria alla Santa Fede, ed al buon costume; e vi ho riconosciuta inoltre, dovizia di erudidizione, utili avvertimenti, vivacità, ed eleganza di stile, per cui la gindico meritevole della stampa.

Li 20. Febbraro 1825.

Saverio Barlocci

Professore di Fisica Speriment.

I M P R I M A T U R

Si videbitur Rm̄o Pat. Sac. Palatii Ap. Magistro.

J. Della Porta Patriarch. Constantinop.

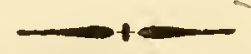

I M P R I M A U R

Fr. Thomas Dominicus Piazza O. P., S. T. Masg. et Rmi S. P. A. M. Soc. 



\section{SPIEGAZIONE}

\section{E L L E F I G U R E.}

Fıg. I. n. I. F emmina dell' Acrydium italicum di grandez. za natmrale..( pag. I 6. )

1. 2. Astuccio ed ala dell' $A$. italicum. (pag. I8.)

Fig. 2. 1. 1. Femmina delf' $A$. migratorium di grandezza na= turale. (pag. 38.)

n. 2. Astuccio ed ala dell' $A$. migratorium.

$E_{1 G}$. 3. n. I. Larva dell' $A$. italicum pin grande del natmale.

11. 2. Lunghezza naturale della larva dell'A italicum.

n. 3. Labbro superiore dell' $A$. italicum pin grande del naturale. (pag. I6.)

n. 4. Labbro inferiore con suoi palpi labiali dell' $A$. italicume-un poco più grande del naturale. ( pag. I 7.)

n. 5. Una delle due mandibole dell' $A$. italicum $u n$ poco più grande del naturale. (pag. I 7 .)

n. 6. Una delle due mascelle dell' $A$. italicum con uno de' palpi mascellari un poco più grande del naturale.

n. 7. Una delle due antenne più grande del naturale.

13. 8. Una delle due estrencità posteriori dell' $A$. italicum più grande del naturale.

Frg. 4. n. I. Ninfa dell' $A$. italicum più grande del naturale.

n. 2. Lunghezza naturale della ninfa dell'A. italicum.

FIG. 5.

Il maschio di un insetto che trovasi nella parte colorata dell'ala dell' $A$. italicum, da noi denominato Leptus $A$. italici. (pag. 18. nota)

Fio. 6. La femmina dello stesso Leptus che per errore è rappresentata più piccola del maschio.(p.i 8. nota )

Fig. 7. n. 1. Gilindro intero, o cannello che racchiude le ova dell' A. italicum. ( pag. 33.)

n. 2. Gilindro rotto con uno strato di ova alla super. ficie. ( pag. 33.)

Fic. 8. Ova dell A. italicum. (pag. 33.) 

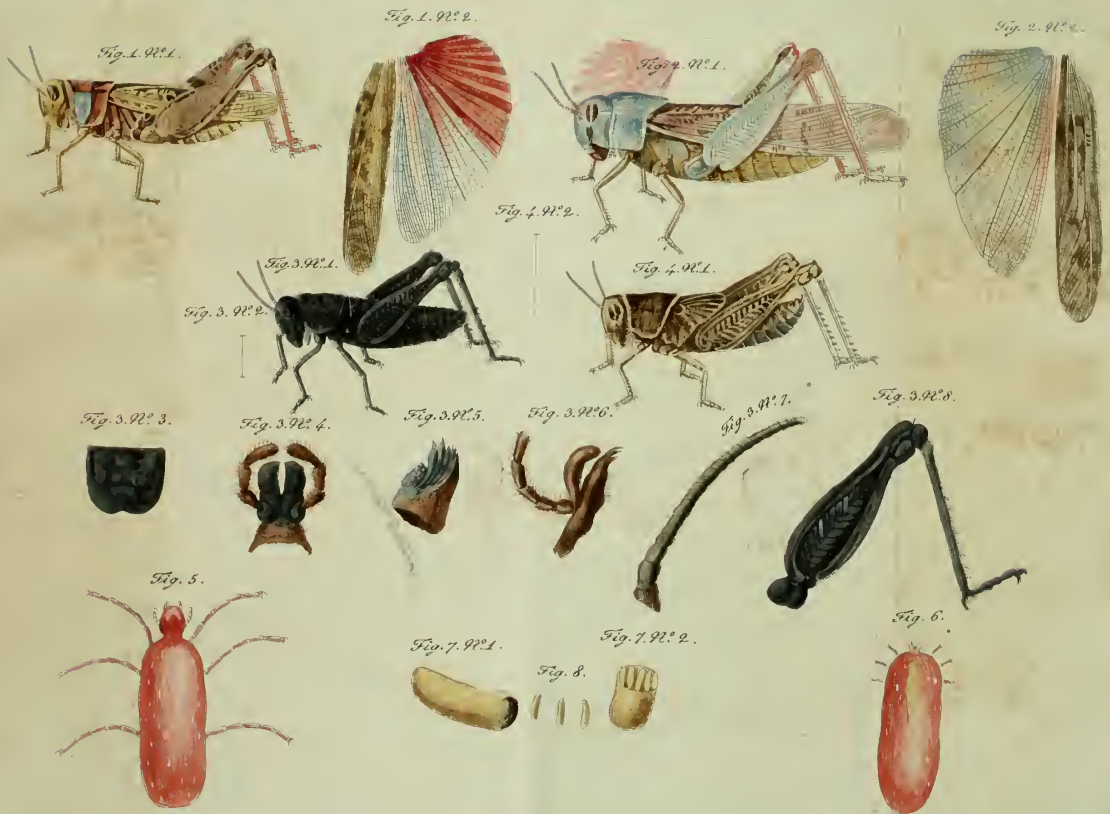

Fin.7.99:1 Fig.7.92:0
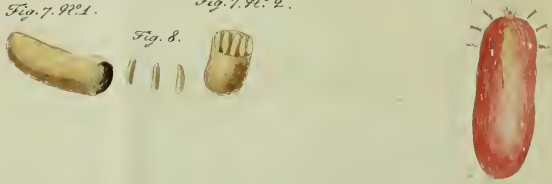




DIGEST OF TIIE

\section{LIBRALY liEGULATIONS.}

No book shall be titken from the Library without the record of the Librarian.

Xo person shall be allowed to retain more than five volumes at any one time, culess by special vote of the Conncil.

Pooks may be kept out one calendar month: no longer without renewal, and renewal may not be granted more than twice.

A fine of fire cents per day incurred for every volume not returued within the time specified by the rules.

The Librarian nuy demand the return of a book after the expiration of ten days from the date of borrowing.

Certain books, so designated, canuot be taken from the Library without special permission.

All books must be returned at least two weeks previous to the Annmal Meeting.

Persous are responsible for all injury or loss of books charged to their name. 
ESt

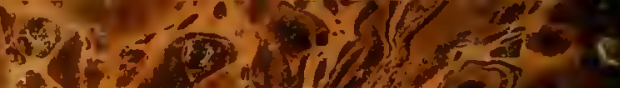

pason. (2) $-\infty$ teg 12 Sor.

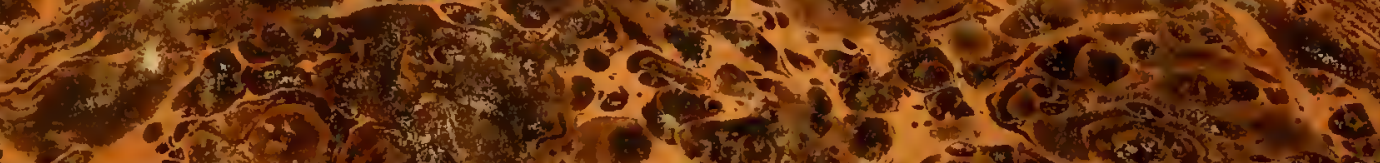
P.t.

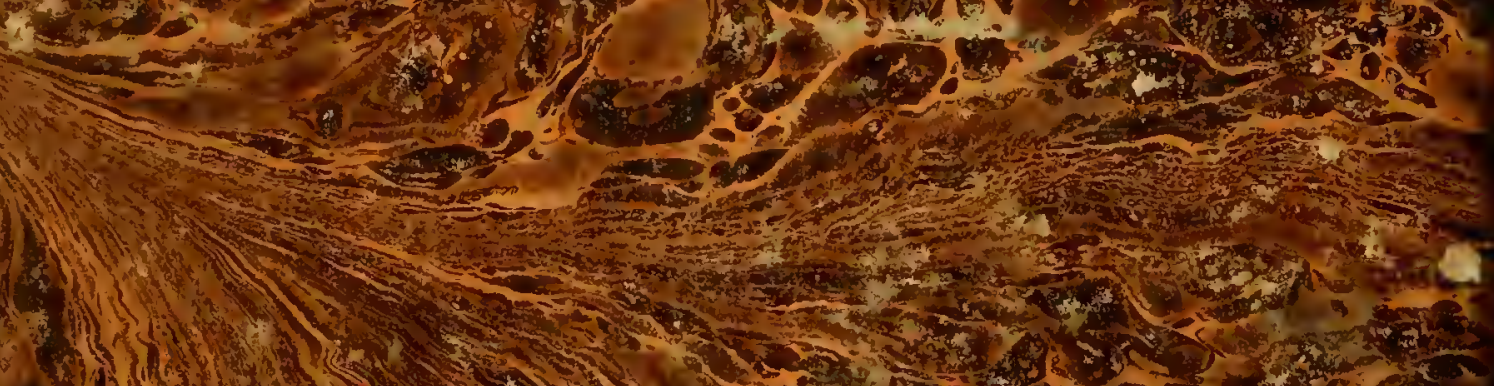

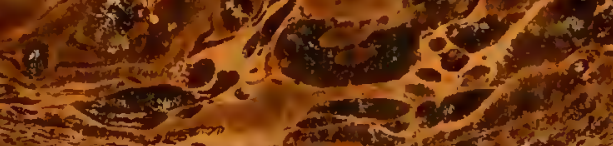

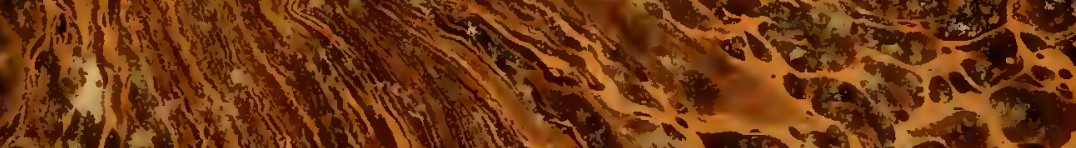

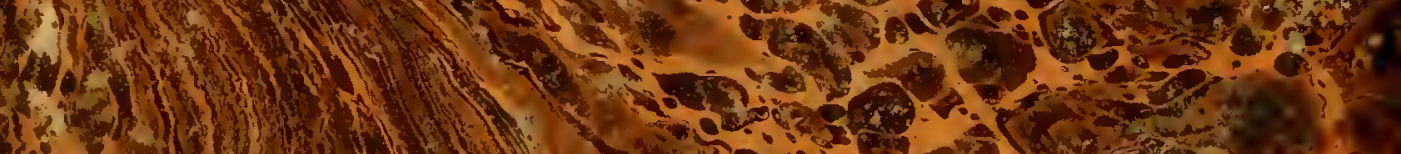

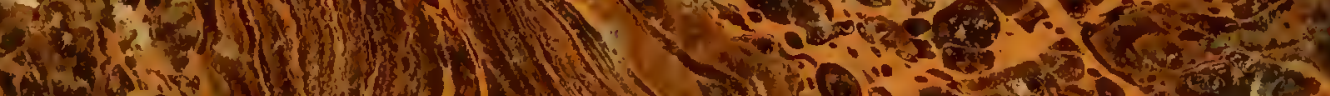

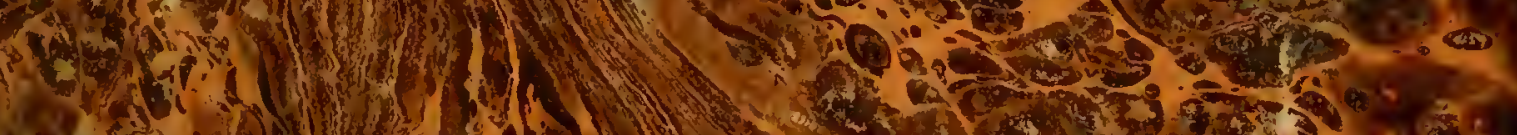

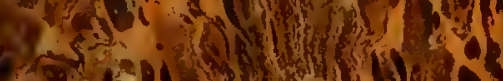

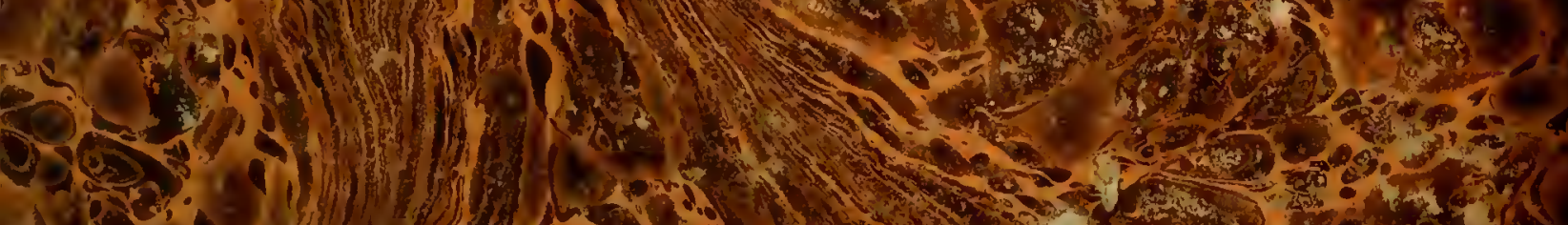

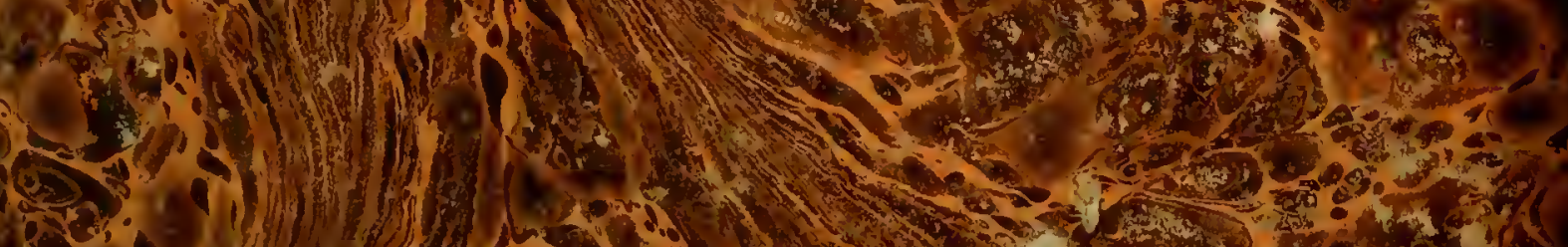
$\rightarrow \infty$

*i)

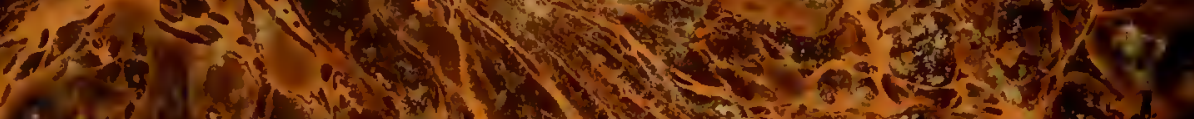
F.

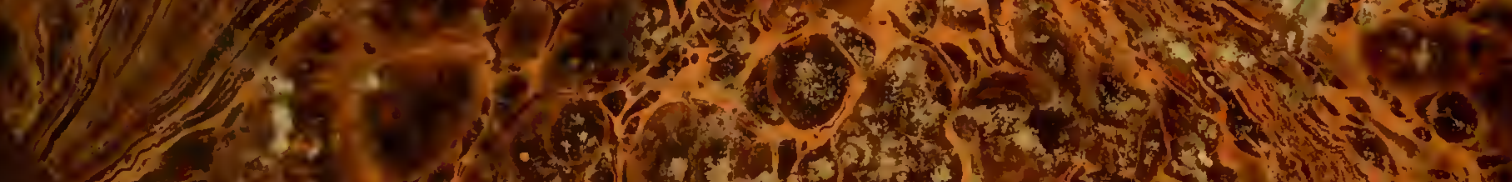

